\title{
Relationship between Membrane Phosphatidylinositol-4,5- Bisphosphate and Receptor-Mediated Inhibition of Native Neuronal M Channels
}

\author{
Joanna S. Winks, ${ }^{1}$ Simon Hughes, ${ }^{2}$ Alexander K. Filippov, ${ }^{2}$ Lucine Tatulian, ${ }^{2}$ Fe C. Abogadie, ${ }^{2}$ David A. Brown, ${ }^{2}$ and \\ Stephen J. Marsh ${ }^{2}$ \\ ${ }^{1}$ Ion Channel Pharmacology Group, IPC 388, Pfizer Global Research and Development, Sandwich Laboratories, Sandwich, Kent CT13 9NJ, United Kingdom, \\ and ${ }^{2}$ Department of Pharmacology, University College London, London WC1E 6BT, United Kingdom
}

The relationship between receptor-induced membrane phosphatidylinositol-4'5'-bisphosphate ( $\left.\mathrm{PIP}_{2}\right)$ hydrolysis and M-current inhibition was assessed in single-dissociated rat sympathetic neurons by simultaneous or parallel recording of membrane current and membrane-to-cytosol translocation of the fluorescent $\mathrm{PIP}_{2}$ /inositol 1,4,5-trisphosphate $\left(\mathrm{IP}_{3}\right)$-binding peptide green fluorescent proteintagged pleckstrin homology domain of phospholipase C (GFP-PLC $\delta$-PH). The muscarinic receptor agonist oxotremorine-M produced parallel time- and concentration-dependent M-current inhibition and GFP-PLC $\delta$-PH translocation; bradykinin also produced parallel time-dependent inhibition and translocation. Phosphatidylinositol-4-phosphate-5-kinase (PI5-K) overexpression reduced both M-current inhibition and GFP-PLC $\delta$-PH translocation by both oxotremorine-M and bradykinin. These effects were partly reversed by wortmannin, which inhibits phosphatidylinositol-4-kinase (PI4-K). PI5-K overexpression also reduced the inhibitory action of oxotremorine-M on PIP ${ }_{2}$-gated G-protein-gated inward rectifier (Kir3.1/3.2) channels; bradykinin did not inhibit these channels. Overexpression of neuronal calcium sensor-1 protein (NCS-1), which increases PI4-K activity, did not affect responses to oxotremorine-M but reduced both fluorescence translocation and $\mathrm{M}$-current inhibition by bradykinin. Using an intracellular $\mathrm{IP}_{3}$ membrane fluorescencedisplacement assay, initial mean concentrations of membrane [PIP $]$ were estimated at $261 \mu \mathrm{M}$ (95\% confidence limit; 192-381 $\mu \mathrm{M})$, rising to $693 \mu \mathrm{M}(417-1153 \mu \mathrm{M})$ in neurons overexpressing PI5-K. Changes in membrane [PIP ${ }_{2}$ ] during application of oxotremorine-M were calculated from fluorescence data. The results, taken in conjunction with previous data for KCNQ2/3 (Kv7.2/Kv7.3) channel gating by $\mathrm{PIP}_{2}$ (Zhang et al., 2003), accorded with the hypothesis that the inhibitory action of oxotremorine-M on $\mathrm{M}$ current resulted from depletion of $\mathrm{PIP}_{2}$. The effects of bradykinin require additional components of action, which might involve $\mathrm{IP}_{3}$-induced Ca ${ }^{2+}$ release and consequent M-channel inhibition (as proposed previously) and stimulation of $\mathrm{PIP}_{2}$ synthesis by $\mathrm{Ca}^{2+}$-dependent activation of NCS- 1 .

Key words: $\mathrm{PIP}_{2} ; \mathrm{M}$ current; neuronal excitability; G-protein-coupled receptors; PLC; sympathetic neurons

\section{Introduction}

$\mathrm{M}$ channels are low-threshold $\mathrm{K}^{+}$channels that regulate neuronal excitability in both the CNS and the PNS (Brown and Adams, 1980; Brown, 1988; Marrion, 1997). They are composed of subunits of the KCNQ (Kv7) gene family (Wang et al., 1998; Jentsch, 2000). The channels are inhibited by stimulating $G_{q / 11}$-coupled receptors, for example in sympathetic neurons by $\mathrm{M}_{1}$ muscarinic acetylcholine receptors $\left(\mathrm{M}_{1}-\mathrm{mAChRs}\right)$ (Marrion et al., 1989;

Received Aug. 6, 2004; revised Feb. 11, 2005; accepted Feb. 11, 2005.

This work was supported by grants from the UK Medical Research Council (MRC) and The Wellcome Trust. J.S.W. was supported by a prize studentship from The Wellcome Trust. We thank Prof. Don Jenkinson (Department of Pharmacology, University College London, London, UK) for his critical evaluation of our equations, Dr. David Ogden (MRC, Mill Hill, UK) for his suggestions regarding the aqueous vesicle experiments, and Joanne Reilly for her tissue culture and intranuclear injection expertise. We also thank Drs. Tobias Meyer (Stanford University, Stanford, CA), Ken Young (University of Leicester, Leicester, UK), J. Nathan Davis (Louisiana State University Health Sciences Center, Shreveport, LA), Jamie Weiss (University of Sheffield, Sheffield, UK), and F. Lesage (Sophia Antipolis, Valbonne, France) for the gift of cDNA plasmids.

Correspondence should be addressed to Dr. S. Marsh, Department of Pharmacology, University College London, Gower Street, London WC1E6BT, UK. E-mail: s.marsh@ucl.ac.uk.

D01:10.1523/JNEUROSCI.3231-04.2005

Copyright $\odot 2005$ Society for Neuroscience $\quad$ 0270-6474/05/253400-14\$15.00/0
Bernheim et al., 1992) and by bradykinin (BK) $\mathrm{B}_{2}$ receptors (Jones et al., 1995). The activated G-protein subunit [principally $\mathrm{G} \alpha_{\mathrm{q}}$ in the rat sympathetic neuron (Haley et al., 1998)] does not appear to gate the $\mathrm{M}$ channels directly but instead induces their closure by some indirect mechanism (Selyanko et al., 1992; Marrion, 1993).

Recent evidence suggests that receptor-induced closure results from hydrolysis of the membrane phospholipid, phosphatidylinositol-4' $5^{\prime}$-bisphosphate $\left(\mathrm{PIP}_{2}\right)$ (Suh et al., 2004). As with a number of other channels (Hilgemann et al., 2001; Runnels et al., 2002; Loussouarn et al., 2003), $\mathrm{PIP}_{2}$ is required to maintain KCNQ channels in their open state (Zhang et al., 2003), and resynthesis of $\mathrm{PIP}_{2}$ is necessary for recovery from $\mathrm{M}$-channel inhibition produced by mAChRs (Suh and Hille, 2002) and by nucleotide receptors (Ford et al., 2003). Thus, mAChR-induced closure might result directly from the local depletion of $\mathrm{PIP}_{2}$ consequent on its hydrolysis. In contrast, BK-induced M-channel inhibition more likely stems from the action of a downstream product of $\mathrm{PIP}_{2}$ hydrolysis, inositol 1,4,5-trisphosphate $\left(\mathrm{IP}_{3}\right)$, which releases $\mathrm{Ca}^{2+}$ from intracellular stores and thereby closes 
channels via binding to calmodulin (Selyanko and Brown, 1996; Cruzblanca et al., 1998; Bofill-Cardona et al., 2000; Delmas et al., 2002; Gamper and Shapiro, 2003). Another product of $\mathrm{PIP}_{2}$ hydrolysis, diacylglycerol, might contribute to $\mathrm{mAChR}$-induced inhibition of $\mathrm{M}$ channels through activation of protein kinase $\mathrm{C}$ and subsequent channel phosphorylation (Hoshi et al., 2003). These alternative scenarios are summarized by Delmas et al. (2004).

Because both muscarinic agonists and bradykinin are clearly capable of activating phospholipase C (PLC) in sympathetic neurons (Del Rio et al., 1999), we examined more closely the relationship between $\mathrm{PIP}_{2}$ hydrolysis and $\mathrm{M}$-channel closure in these neurons. For this, we used a fluorescent $\mathrm{IP}_{3} / \mathrm{PIP}_{2}$-binding peptide [the green fluorescent protein-tagged pleckstrin homology domain of PLC $\delta$ (GFP-PLC $\delta$-PH)] (Stauffer et al., 1998; Varnai and Balla, 1998; Nahorski et al., 2003). We then asked what happens when the synthesis of $\mathrm{PIP}_{2}$ is enhanced by overexpressing the enzyme phosphatidylinositol-4-phosphate-5-kinase (PI5-K) (Ishihara et al., 1996) or the neuronal calcium sensor-1 protein (NCS-1; frequenin), which increases the activity of phosphatdidylinositol-4-kinase (PI4-K) (Burgoyne et al., 2004). Finally, we compared these effects of PI5-K overexpression with its effects on receptor-induced inhibition of G-protein-gated inward rectifier (GIRK; Kir3.1+Kir3.2)channels, which has been attributed to $\mathrm{PIP}_{2}$ depletion (Kobrinsky et al., 2000; Lei et al., 2001; Meyer et al., 2001; Bender et al., 2002).

Preliminary reports of our observations have been published previously (Winks and Marsh, 2003; Winks et al., 2003)

\section{Materials and Methods}

Neuron cultures. Superior cervical ganglia (SCGs) were isolated from 17-d-old Sprague Dawley rats (either gender) after terminal anesthesia using $\mathrm{CO}_{2}$, followed by decapitation in accordance with United Kingdom Home Office regulatory procedures. Ganglia were digested in collagenase solution (800 international units of collagenase class 2; SigmaAldrich, Dorset, UK), $12 \mathrm{mg}$ of bovine serum albumin (BSA; SigmaAldrich), and $2 \mathrm{ml}$ of HBSS plus HEPES for $15 \mathrm{~min}$ at $37^{\circ} \mathrm{C}$. Ganglia were then rinsed with HBSS plus 10 mM HEPES and placed in trypsin solution [ $2 \mathrm{mg}$ of trypsin, bovine type XII S (Sigma-Aldrich), $12 \mathrm{mg}$ of BSA, $2 \mathrm{ml}$ of HBSS plus $10 \mathrm{~mm}$ HEPES) for $30 \mathrm{~min}$ at $37^{\circ} \mathrm{C}$. Digested fragments were then transferred into $2 \mathrm{ml}$ of growth medium [ $42 \mathrm{ml}$ of L- 15 plus GlutaMAX (Sigma-Aldrich), $8.5 \mathrm{ml}$ of $1.26 \% \mathrm{NaHCO}_{3}$ (24 mM; Invitrogen, San Diego, CA), $5 \mathrm{ml}$ of fetal calf serum (Sigma-Aldrich), $1.15 \mathrm{ml}$ of $30 \%$ glucose, $0.61 \mathrm{ml}$ of $200 \mathrm{~mm}$ L-glutamine ( $2 \mathrm{~mm}$; Invitrogen), $50 \mathrm{ng} / \mathrm{ml}$ NGF 7S (Sigma-Aldrich)], and the mixture was triturated and then centrifuged five times, after which the remaining cell suspension was spun for $5 \mathrm{~min}$ at $800 \mathrm{rpm}$. The supernatant was then discarded, and the cells were resuspended in $5 \mathrm{ml}$ of growth media. For electrophysiological recording/imaging, $\sim 500 \mu \mathrm{l}$ of cell solution was added to each sterile culture/recording chamber consisting of a glass ring (diameter, $16 \mathrm{~mm}$; height, $3 \mathrm{~mm}$ ) attached to a laminin substrate-coated borosilicate glass coverslip $(22 \times 22 \mathrm{~mm}$; thickness, $0.13-0.17 \mathrm{~mm}$; BDH Chemicals, Poole, UK) placed inside a $35 \mathrm{~mm}$ Petri dish. Chambers were then incubated at $37^{\circ} \mathrm{C}$ in $95 \% \mathrm{O}_{2} / 5 \% \mathrm{CO}_{2}$ for at least $4 \mathrm{~h}$ to allow neurons to adhere to the coverslip. Neurons were usually transfected/recorded between 1 and $4 \mathrm{~d}$ after plating.

Transfection. Neurons were transfected with cDNA 1-2 d after culture by intranuclear microinjection of cDNA plasmids. Sharp electrodes ( $>50 \mathrm{M} \Omega$ resistance) were filled with plasmid dissolved in injection solution (in mM: $154 \mathrm{NaCl}, 5 \mathrm{HEPES}, 2.5 \mathrm{KCl}$, and $0.5 \mathrm{MgCl}_{2}, \mathrm{pH}$ adjusted to 7.4 using $\mathrm{NaOH}$ ) at a concentration of $100 \mathrm{ng} / \mu \mathrm{l}$ of each cDNA plasmid to be injected. Injections were performed using an Eppendorf Scientific (Westbury, NY) automated microinjector (Transjector 5246) or (for Kir 3.1/3.2 cDNAs) a Narishige (Tokyo, Japan) micromanipulator. Neurons were incubated for $1 \mathrm{~d}$ before use unless otherwise stated. The following plasmids were used: pleckstrin-homology domain of phospholipase C- $\delta_{1}$ in enhanced GFP (eGFP)-C1 vector (GFP-PLC- $\delta$ $\mathrm{PH}$ ) [obtained from T. Meyer (Stanford University, Stanford, CA) via K. Young (University of Leicester, Leicester, UK)]; rat neuronal calcium sensor protein-1 in pcDNA 3.1 vector (obtained from J. Weiss, University of Sheffield, Sheffield, UK); murine phosphatidylinositol 4-phosphate-5-kinase-I $\beta$ in pcDNA 3.1 vector containing GFP sequence (GFPmPIP5K-I $\beta$; here, PI5-K; obtained from J. N. Davis, Louisiana State University Health Sciences Center, Shreveport, LA); mutant phosphatidylinositol 4-phosphate-5-kinase-I $\beta$, lacking kinase activity, in pcDNA 3.1 vector containing GFP sequence [GFPmPIP5K-I $\beta(\mathrm{K} 179 \mathrm{M})$; here, mutant PI5-K; obtained from J. N. Davis); Kir3.1 and Kir3.2 (GIRK1 and GIRK2) in pCI and pRc/cytomegalovirus (CMV) vectors, respectively (from F. Lesage, Sophia Antipolis, Valbonne, France); enhanced green fluorescent protein in pcDNA 3.1 vector (eGFP) and red fluorescent cloning vector (pDSRed2-N1; Clontech, Cambridge, UK). All plasmids used contained the CMV promoter. Plasmids were propagated in $\mathrm{DH} 5 \alpha$ (Invitrogen) Escherichia coli and purified using Qiagen (Hilden, Germany) maxiprep columns.

Electrophysiological recording. The perforated-patch configuration of the patch-clamp technique was used (except where otherwise stated) with amphotericin B as the pore-forming agent (Rae et al., 1991). Neurons were superfused via a gravity-driven system $(10-15 \mathrm{ml} / \mathrm{min}$; bath volume, $500 \mu \mathrm{l}$ ) with an external solution containing the following (in mM): $136 \mathrm{NaCl}, 11.1$ glucose, 5 HEPES, $3 \mathrm{KCl}, 2.5 \mathrm{CaCl}_{2}$, and $1.5 \mathrm{MgCl}_{2}$, $\mathrm{pH}$ adjusted to 7.4 with $\mathrm{NaOH}$. For inward rectifier (Kir 3.1/3.2, GIRK) current recording, the $\mathrm{KCl}$ concentration in the bath solution was increased to $6 \mathrm{~mm}(\mathrm{KCl}$ substituted for $\mathrm{NaCl})$ and tetrodotoxin $(0.5 \mu \mathrm{M})$ added to block the $\mathrm{Na}^{+}$current. Pipettes with 2-3 M $\Omega$ resistance were filled with an internal solution containing the following (in $\mathrm{mM}$ ): $\mathrm{M}$ current, $30 \mathrm{KCl}, 100 \mathrm{~K}$ acetate, 20 HEPES, 10 EGTA, and $3 \mathrm{MgCl}_{2}$, pH 7.2 with $\mathrm{KOH}$; Kir/GIRK current, $20 \mathrm{KCl}, 90 \mathrm{~K}$ acetate, $3 \mathrm{MgCl}_{2}, 40 \mathrm{HEPES}$, and 0.1 BAPTA, pH 7.4 with $\mathrm{KOH}$; and $\mathrm{N}$-type $\mathrm{Ca}^{2+}$ current, $140 \mathrm{CsCl}$, $1 \mathrm{MgCl}_{2}, 0.1$ BAPTA, $0.1 \mathrm{CaCl}_{2}$, and 10 HEPES, CsOH to $\mathrm{pH}$ 7.4. All recordings were made at room temperature $\left(19-22^{\circ} \mathrm{C}\right)$ unless otherwise stated. Currents were recorded using an Axopatch 200A or 200B amplifier (except where otherwise stated), filtered at $1 \mathrm{kHz}$, and digitized at $1-10 \mathrm{kHz}$. Pipette series resistances were compensated $60-90 \%$.

$M$ currents. Cells were held at $-20 \mathrm{mV}$ to preactivate the current. Currents were then deactivated at intervals of $10-15 \mathrm{~s}$ by $1 \mathrm{~s}$ hyperpolarizing steps to $-50 \mathrm{mV}$. Current amplitudes were measured from extrapolated deactivation current tails using a biexponential curve-fitting procedure.

$\mathrm{Ca}^{2+}$ currents. $\mathrm{N}$-type $\mathrm{Ca}^{2+}$ currents were recorded by holding the cell at $-70 \mathrm{mV}$ and depolarizing to $+5 \mathrm{mV}$ for $200 \mathrm{~ms}$. Currents were leak subtracted by blockade with $5 \mathrm{~mm} \mathrm{CoCl}{ }_{2} \cdot \mathrm{Ca}^{2+}$ charge entry was determined from the integral of the current (after leak subtraction) as described by Wanaverbecq et al. (2003).

G-protein-gated inward rectifier potassium currents. GIRK currents were recorded from cells preinjected with Kir3.1/3.2 and eGFP cDNA plasmids and identified by eGFP fluorescence, as described by Fernandez-Fernandez et al. (1999) but with the differences that perforated-patch recording was used and the external $\mathrm{K}^{+}$concentration was $6 \mathrm{~mm}$. Currents were generated by applying $200 \mathrm{~ms}$ voltage ramps between -140 and $-40 \mathrm{mV}$ every $5 \mathrm{~s}$ from a holding potential of -40 $\mathrm{mV}$ and recorded using an Axoclamp 2B switch-clamp amplifier in discontinuous mode (sample rate, $6-8 \mathrm{kHz}$ ).

Fluorescence microscopy. Live neurons were imaged using a Nikon (Tokyo, Japan) Diaphot inverted microscope with a $40 \times$ oil-immersion lens. Excitation light was provided by a monochromator (Polychrome II; TILL Photonics, Martinsried, Germany) controlled via an Apple Macintosh G4 computer and Openlab imaging software (Improvision, Coventry, UK). Images were captured on a 12-bit grayscale digital camera (C488000; Hamamatsu, Shizouka, Japan) and pseudo-color palettes overlaid according to the dye imaged. Images were acquired with minimum delay, according to the exposure time of the camera, but usually more than one image per second.

Digital deconvolution. Images obtained with the above equipment are subject to a certain amount of blurring, caused by light "haze" emitted from above and below the plane of focus. To remove this blurring with- 
out the use of laser confocal microscopy, digital deconvolution was used. This technique corrects and removes the noise and haze originating from images in other focal planes using mathematical algorithms, the simplest of which is the "nearest neighbor algorithm" (Agard et al., 1989; Castleman, 1996). This algorithm calculates the contribution of light noise from the focal planes above and below the desired slice and subtracts them. An automation was designed in-house, using Openlab software, which automatically focused the microscope to the bottom of the cell, and then programmed it to acquire several optical slices $(\approx 20)$ in $0.5 \mu \mathrm{m}$ steps through the cell. An image from a particular focal plane was corrected using the nearest five-neighbors algorithm (i.e., using five optical slices above and five below the chosen plane). The algorithm calculates the point-spread function of the microscope, which can be estimated once the objective, immersion solution, camera resolution, and binning are known. The images produced by this method were indistinguishable from those obtained from a "conventional" laser-scanning microscope (SP2; Leica, Nussloch, Germany), which essentially (at this resolution) gave the same results.

Simultaneous electrophysiological and fluorescence recording. After locating a fluorescent cell, it was then patched at a holding potential of -60 $\mathrm{mV}$ using only transmitted light. The light was then switched off while the patched membrane permeabilized, because amphotericin B is light sensitive. When the access resistance was suitably low $(<15 \mathrm{M} \Omega)$, the fluorescent light was switched on and the focus and camera exposure time were adjusted. The membrane potential was then set to the holding potential for M-current activation $(-20$ to $-30 \mathrm{mV})$. Hyperpolarizing steps to $-50 \mathrm{mV}$ to deactivate $\mathrm{M}$ currents were initiated by a digital pulse, which was triggered by commencement of the imaging recording, to synchronize the two recordings.

$\mathrm{Ca}^{2+}$ imaging. Cells were incubated with $2 \mu \mathrm{M}$ fura-2 AM for $30 \mathrm{~min}$ at $37^{\circ} \mathrm{C}$ and then washed for $20 \mathrm{~min}$ before commencing experimentation. Alternate images at 350 and $380 \mathrm{~nm}$ excitation wavelengths were recorded at $1 \mathrm{~Hz}$ and background subtracted, and the ratio images were calibrated using an algorithm formulated in a separated set of experiments. The equipment was calibrated by cell dialysis in the whole-cell configuration using intracellular solutions from a calcium calibration buffer kit (Molecular Probes, Eugene, OR) containing fura-2 acid (100 $\mu \mathrm{M})$.

Cell volume measurements. Cell volume was determined using a Leica SP2 confocal-scanning microscope. A z-stack consisting of a series of 0.2 $\mu \mathrm{m}$ optical slices was taken through cells that had been preloaded with the intracellular fluorescent marker calcein (calcein-AM, $2 \mu \mathrm{M}$ for $35 \mathrm{~min}$ at $37^{\circ} \mathrm{C}$; excitation/emission wavelengths, $480 / 530 \mathrm{~nm}$ ). These twodimensional slices were then three-dimensionally reconstructed, and the cell surface was rendered using the Imaris software package (Bitplane, Zurich, Switzerland). Volumes of the isolated soma were determined by voxel counting of the entire calibrated and reconstructed volume.

Free intracellular space. To determine the free intracellular space available to a small hydrophilic molecule such as inositol-1,4,5-trisphosphate (see Results), we compared the fluorescence intensity of known concentrations of a low-molecular-weight fluorophore [4,4-difluoro-4-bora3a,4a-diaza-s-indacene fluorophoro (BODIPY-FL); molecular weight, 292; Molecular Probes] contained within aqueous vesicles with that of the same concentrations fully dialyzed into patch-clamped sympathetic neurons. Aqueous vesicles in a silicon elastomer (Sylgard 182; Dow Corning, Midland, MI) were fashioned after the methods of Canepari et al. (2001). BODIPY-FL was initially dissolved in intracellular solution and then $50 \mu \mathrm{l}$ of this solution was rapidly stirred into $1 \mathrm{ml}$ of uncured elastomer. A small aliquot was placed on a microscope slide and covered with a glass coverslip. The microscope slide was then heated on a hotplate at $60^{\circ} \mathrm{C}$ for $5 \mathrm{~min}$ to set, firmly embedding the vesicles within. The microscope was optimized for recording the fluorescence intensity of the highest concentration of BODIPY-FL $(100 \mu \mathrm{M})$ contained within spherical aqueous vesicles of comparable size to sympathetic neurons (19-23 $\mu \mathrm{m}$ diameter) by adjusting the excitation intensity ( $480 \mathrm{~nm}$ ) to minimize photobleaching ( $<5 \%$ in $10 \mathrm{~min}$ ) and optimizing the 12-bit image capture by using multiple frame-averaging $(n=5)$ background subtraction and digital deconvolution. Once set, these parameters were used throughout the entire experiment. The dialysis of BODIPY-FL into SCG cells was monitored by taking brief fluorescent images (100 ms) every
A

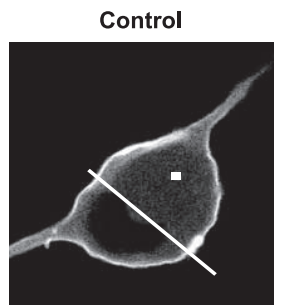

B

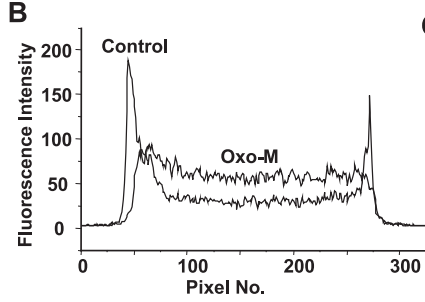

$C_{70}$ Oxo-M

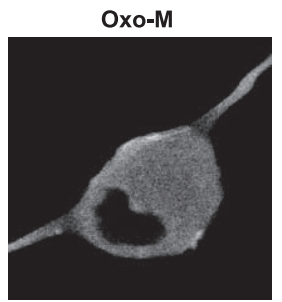

D

E
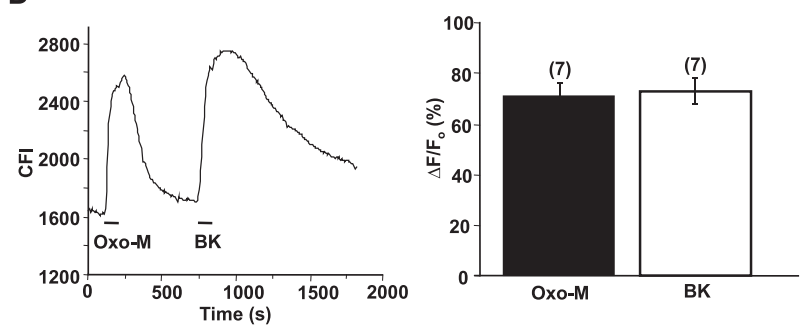

Figure 1. Agonist-induced translocation of GFP-PLC $\delta$-PH. A, Scanning confocal microscope images (8-bit resolution; i.e., 256 gray scales) of GFP-PLC $\delta$-PH fluorescence distribution in a sympathetic neuron before and during application of $10 \mu \mathrm{m} 0 \mathrm{xo}-\mathrm{M}$. $\boldsymbol{B}$, Plot of fluorescence intensity across a single line scan ( $\boldsymbol{A}$, white line) before and during the peak of the $0 \times 0-\mathrm{M}$ response. $C$, Continuous time plot of cytosolic fluorescence intensity recorded in a single region of interest ( $\boldsymbol{A}$, white box). $\boldsymbol{D}$, Changes in CFI (12-bit resolution; i.e., 4096 gray scales) in a single neuron produced by successive applications of $10 \mu \mathrm{m} 0 \mathrm{X0}-\mathrm{M}$ and $100 \mathrm{~nm} B K$. $E$, Mean changes in cytosolic fluorescence in seven neurons produced by $10 \mu \mathrm{M} 0 \mathrm{xo}-\mathrm{M}$ and $100 \mathrm{~nm}$ BK applied sequentially as in $\boldsymbol{D}$. The change in fluorescence is given as $\Delta F / F_{0} \times 100 \%$, where $\Delta F=F-$ $F_{0}, F$ is peak fluorescence after agonist application, and $F_{0}$ is baseline fluorescence before agonist application.

minute for $15 \mathrm{~min}$, after which a digital deconvolved image was recorded. To minimize errors, we used the same BODIPY-FL-containing intracellular solutions for whole-cell dialysis and aqueous vesicle measurement. Fluorescence intensity was measured using a binary mask generated by image thresholding. This allows an average intensity within boundaries of both the dialyzed cells and aqueous vesicles to be measured. The free intracellular space was determined by subjecting the raw data to linear regression and calculating the ratio of the slopes of the lines generated (see Fig. $8 \mathrm{~A}$ ).

Immunocytochemistry. Cells for immunocytochemistry were cultured on glass coverslips in four-well plates (Nunclon; Nunc, Roskilde, Denmark). Cells were fixed with $0.2 \%$ gluteraldehyde $/ 2 \%$ paraformaldehyde (in PBS; Sigma-Aldrich) for $20 \mathrm{~min}$ at room temperature. Fixed cells were then permeabilized with $0.1 \%$ Triton X-100 (Sigma-Aldrich) in PBS for $15 \mathrm{~min}$. After washing the cells several times in PBS, they were incubated for $1 \mathrm{~h}$ in a blocking buffer consisting of $10 \mathrm{mg} \cdot \mathrm{ml}^{-1}$ BSA (Sigma-Aldrich) in PBS and then for $1 \mathrm{~h}$ in the primary antibody, rabbit anti-NCS-1 (1:200). A secondary antibody (swine anti-rabbit IgG conjugated with tetramethylrhodamine isothiocyanate, 1:200) was then used for visualization. After several washes with PBS, the coverslips were removed from the four-well plates and mounted onto slides using a mounting medium, where they were sealed using clear nail varnish. Slides were refrigerated until examination. The level of auto-fluorescence was estimated by performing the above immunocytochemistry procedures in the absence of primary and secondary antibodies. Nonspecific binding was determined in the absence of the primary antibody. 

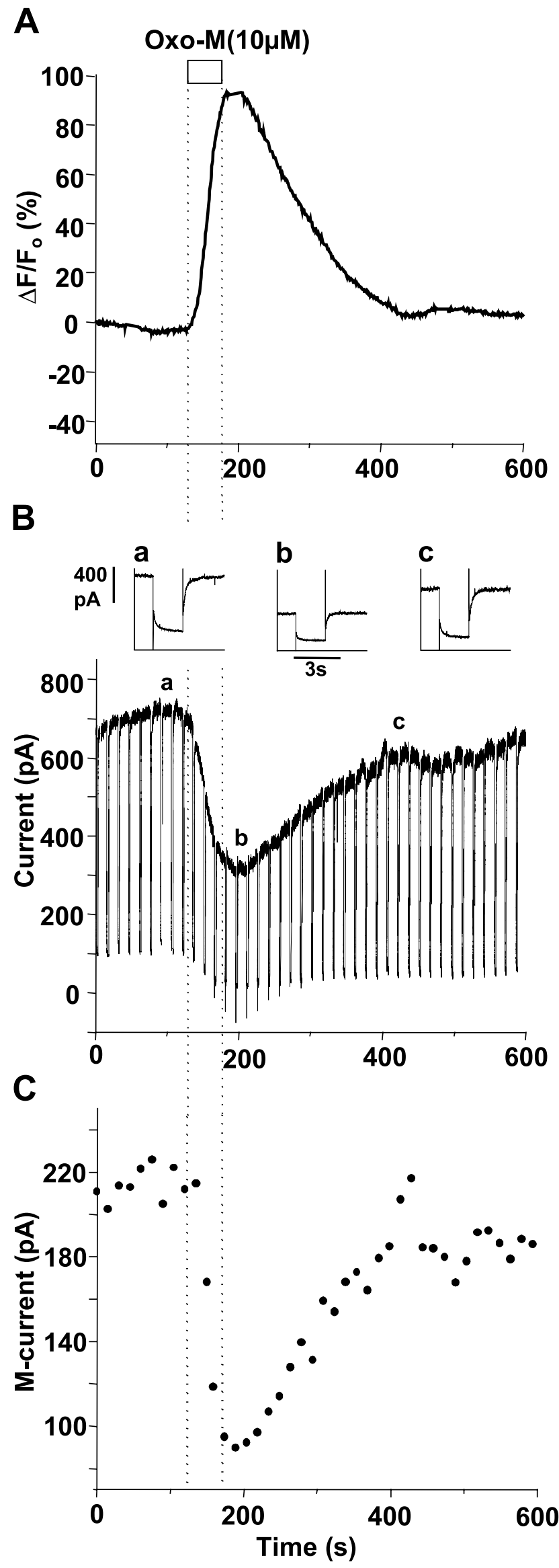

Data. Results are expressed as means \pm SEM (95\% confidence limits). Significance levels were determined by one- or two-tailed $t$ tests as appropriate, and differences were considered real at $p<0.05$.

Drugs and chemicals. Reagents were obtained from BDH Chemicals unless otherwise stated. Oxotremorine-M (Oxo-M), bradykinin (triacetate salt), $\mathrm{IP}_{3}$ (D-myo-inositol 1,4,5-trisphosphate hexasodium salt), 1-(6-((17 $\beta$-3-methoxyester-1,3,5(10)-trien-17-yl)amino)hexyl)-1Hpyrrole-2,5-dione (U73122), and amphotericin B were all obtained from Sigma-Aldrich. Calcein-AM, fura-2 AM, and BODIPY FL were obtained from Molecular Probes. The primary anti-NCS-1 antibody used in the immunocytochemistry was kindly provided by J. Weiss; the secondary antibody was obtained from Santa Cruz Biotechnology (Santa Cruz, CA).

\section{Results}

The response to muscarinic receptor stimulation

In the absence of receptor stimulation, the expressed GFPPLC $\delta$-PH construct was highly localized to the plasma membrane (Fig. $1 A$, control). The addition of the mAChR agonist Oxo-M $(10 \mu \mathrm{M})$ to the bathing fluid produced a rapid and substantial translocation of GFP-PLC $\delta$-PH into the cytosol. Thus, a confocal line scan showed a clear reduction in membrane fluorescence as well as an increase in cytosolic fluorescence (Fig. $1 B$ ). However, because of cell movement, line scans could not be routinely used to quantitate translocation; instead, we did this in the first instance by monitoring the time-dependent increase of fluorescence within a defined region of the cytoplasm, as shown in Fig. $1 C$.

Figure 2 shows that, when simultaneously recorded, the time courses of the changes in cytosolic fluorescence (Fig. $2 \mathrm{~A}$ ), resting membrane current (Fig. $2 B$ ), M-current amplitude (Fig. 2C, deduced from deactivation tail-currents, $B$ ), and their recoveries after washout were closely matched. Likewise, the concentration dependence of the cytosolic fluorescence increase mirrored that for membrane current reduction when recorded simultaneously (Fig. $3 A$ ), and the mean increase in cytosolic fluorescence $\left(\Delta F / F_{0}\right)$ coincided very closely with the mean inhibition of the $M$ current recorded separately (Fig. $3 B$ ). Thus, there is a good concordance between $\mathrm{PIP}_{2}$ hydrolysis, as monitored by GFP-PLC $\delta$-PH translocation, and M-current inhibition for this agonist.

As reported previously (Suh and Hille, 2002), the aminosteroid phospholipase C inhibitor U73122 $(3 \mu \mathrm{M})$ produced a slow inhibition of the $\mathrm{M}$ current and substantially reduced the inhibitory action of $10 \mu \mathrm{M}$ oxotremorine- $\mathrm{M}$ on the residual current, from $66 \pm 2.5 \%(n=6)$ to $23.5 \pm 4.2 \%(n=12)$. U73122 did not change the resting cytosolic fluorescence intensity (CFI) in cells expressing GFP-PLC $\delta$-PH but very strongly reduced the increment in fluorescence after application of $10 \mu \mathrm{M}$ oxotremorine-M, from $72.2 \pm 4.2 \%(n=9)$ to $5.9 \pm 1.9 \%(n=7)$. This reinforces the view that the increased fluorescence induced by oxotremo-

\section{$\leftarrow$}

Figure 2. Simultaneous recording of changes in cytosolic fluorescence $(\boldsymbol{A})$, membrane current $(\boldsymbol{B})$, and $\mathrm{M}$-current amplitude $(\boldsymbol{C})$ produced by oxotremorine-M in a sympathetic neuron. Membrane current was recorded using an amphotericin perforated-patch electrode from a neuron expressing GFP-PLC $\delta$-PH. Cytosolic fluorescence was monitored simultaneously from a defined cytoplasmic region of interest as in Figure 1. 0xo-M (10 $\mu \mathrm{M})$ was added to the bathing fluid for $60 \mathrm{~s}$, indicated by the open bar and vertical dashed lines in $\boldsymbol{A}-\boldsymbol{C}$. A, Percentage change in cytosolic fluorescence from baseline $\left(\Delta F / F_{0} \times 100 \%\right)$. $B$, Membrane current (in picoamperes) recorded at $-20 \mathrm{mV}$. Downward deflections show current transients in response to hyperpolarizing steps to $-50 \mathrm{mV}$. Currents recorded at times $\boldsymbol{a}-\boldsymbol{c}$ are shown on a faster time base above. $\boldsymbol{C}$, Amplitude of M-current deactivation tails (in picoamperes) measured from the initial amplitudes of the deactivation currents illustrated in $\boldsymbol{B}$ plotted against time. Note that oxotremorine-M produced a large increase in fluorescence coincident with the reduction of outward current and M-current deactivation tails. 


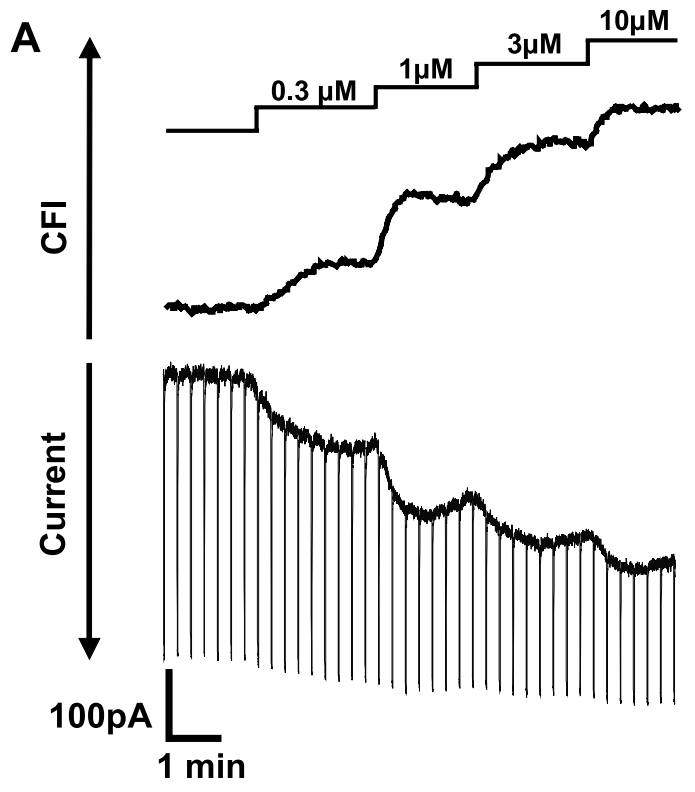

B

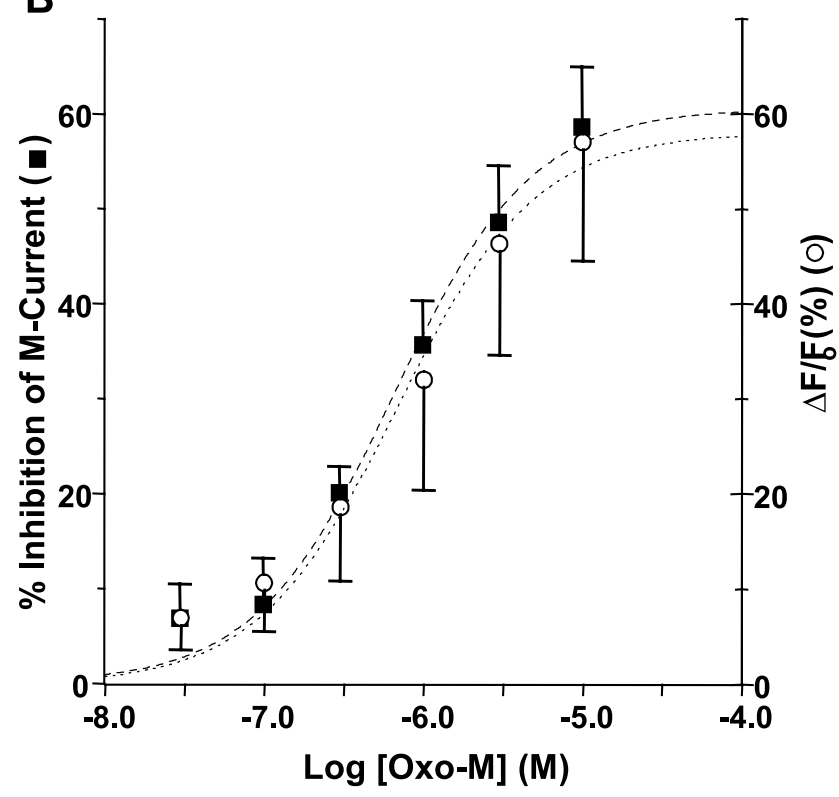

Figure 3. Concentration dependence of oxotremorine-M-induced increases in cytosolic fluorescence and $\mathrm{M}$-current inhibition. $\boldsymbol{A}$, Simultaneous recording of (FI (arbitrary units) and membrane current (in picoamperes) during step-wise increments in the concentration of oxotremorine-M added to the bath-perfusion fluid. $\boldsymbol{B}$, Mean concentration-response curves for percentage of inhibition of $\mathrm{M}$ current (filled squares and dashed line) and percentage increase in cytosolic fluorescence ( $\Delta F / F_{0} \times 100 \%$; open circles and dotted line) produced by increasing concentrations of oxotremorine-M (in log-molar units). 0xotremorine-M was added cumulatively as in $\boldsymbol{A}$. Each point is the mean from measurements in 5-13 neurons; bars show unidirectional SEMs. Curves are drawn according to the equation $y=y_{\max } \times x /(x+K)$. Values for $y_{\max }$ and $K$ were (mean \pm SEM) as follows: M-current inhibition, $61.0 \pm 2.4 \%, 0.68 \pm 0.13 \mu \mathrm{m}$; fluorescence, $58.2 \pm 3.3 \%, 0.68 \pm 0.94 \mu \mathrm{m}$.

rine- $\mathrm{M}$ results from activation of phospholipase $\mathrm{C}$ and consequent hydrolysis of $\mathrm{PIP}_{2}$.

It might be expected that the PLC $\delta$-PH peptide could itself reduce $\mathrm{M}$ current (by sequestering $\mathrm{PIP}_{2}$ ) and/or reduce the inhibition of $\mathrm{M}$ current by agonist (by competing with PLC), as reported previously for thyrotropin-releasing hormone-induced inhibition of GIRK currents (Lei et al., 2001). No significant reduction of $\mathrm{M}$ current or oxotremorine-M-induced inhibition was apparent $1 \mathrm{~d}$ after GFP-PLC $\delta$-PH cDNA injection (as used for the experiments described above). However, $M$ current was substantially and significantly reduced after $3 \mathrm{~d}$ of expression when compared with control neurons cultured for $3 \mathrm{~d}$ simultaneously, from $526 \pm 76$ to $198 \pm 16 \mathrm{pA}$ ( $n=7$ for each).

\section{The response to bradykinin}

Bradykinin (10-100 nM) also induced translocation of the GFPPLC $\delta$-PH construct, similar to that produced by $10 \mu \mathrm{M}$ oxotremorine-M (Fig. $1 D, E$ ). However, the effect of bradykinin differed in two respects from that of oxotremorine-M. First, recovery was much slower. Second, the effect showed strong desensitization, such that it was not possible to obtain two equivalent responses from the same cell. This accords with the slow recovery from, and desensitization of, $\mathrm{M}$-current inhibition by bradykinin (Jones et al., 1995) and unfortunately precluded construction of accurate concentration-response curves.

\section{PI5-K overexpression reduces the effects of both oxotremorine- $\mathrm{M}$ and bradykinin}

Individual neurons were injected intranuclearly with plasmids encoding GFP-tagged versions of either the wild-type PI5-K or a mutant form PI5-K(K179M) devoid of kinase activity (Davis et al., 1997). In both cases, substantial fluorescence in association with the outer membrane was apparent after $2 \mathrm{~d}$ of expression but with additional patches of cytoplasmic fluorescence (perhaps in association with the Golgi/endoplasmic reticulum) (Fig. 4A).

$\mathrm{M}$-current amplitudes (measured from deactivation tailcurrents) (see Materials and Methods) in GFP-PI5-K-expressing cells and mutant PI5-K(K179M)-expressing cells were not significantly different from those in control cells. Mean amplitudes (in picoamperes $) \pm$ SEM were as follows: controls, $215 \pm 16(n=$ 15); PI5-K, $236 \pm 27$ ( $n=19)$; PI5-K(K179M), $223 \pm 35(n=$ 11). Mean deactivation time constants also were not significantly different between the three groups, but time constants varied considerably in PI5-K-expressing neurons and, in some cells, were noticeably slow. This might suggest a $\mathrm{PIP}_{2}$-dependent effect on gating, as previously noted for KCNQ1/KCNE1 channels by Loussouarn et al. (2003). Because of the variability, however, we could not explore this in more detail.

$\mathrm{M}$-current inhibition by both oxotremorine-M and bradykinin was strikingly reduced in wild-type PI5-K overexpressing neurons by $\sim 80$ and $85 \%$, respectively (Fig. $4 \mathrm{~B}$ ). This effect was not observed in cells overexpressing the kinase-deficient mutant PI5-K(K179M). It should be noted that the concentrations of oxotremorine-M and bradykinin used were maximally effective in normal neurons (Fig. 3) (Jones et al., 1995).

To assess the effect of PI5-K overexpression on GFPPLC $\delta$-PH translocation, we replaced the wild-type GFP-tagged PI5-K construct with a construct encoding the red fluorescent protein, pDSRed, and then recorded responses from cells that expressed both red and green fluorescence (Fig. $4 A$ ). The elevation of cytosolic GFP-PLC $\delta$-PH fluorescence produced by both oxotremorine-M and bradykinin was strongly reduced by $\sim 88$ and $55 \%$, respectively (Fig. $4 C$ ). We interpret this to result from the apparent increased level of $\mathrm{PIP}_{2}$ caused by increased PI5-K activity and consequent competitive inhibition of cytosolic $\mathrm{IP}_{3}$ binding to GFP-PLC $\delta$-PH (see below).

To assess whether $\mathrm{IP}_{3}$ production was modified by PI5-K overexpression, we recorded the elevation of intracellular $\mathrm{Ca}^{2+}$ produced by bradykinin using fura-2 AM. [Oxotremorine-M does not produce a detectable $\mathrm{Ca}^{2+}$ signal in these cells, but bradykinin produces a small rise (Cruzblanca et al., 1998; Delmas 
A (i)

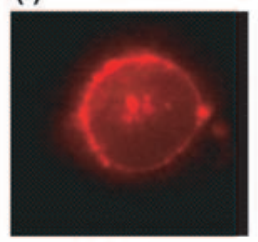

PI5-K (ii)

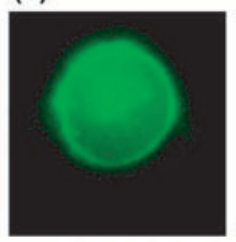

GFP-PLCD-PH (iii)

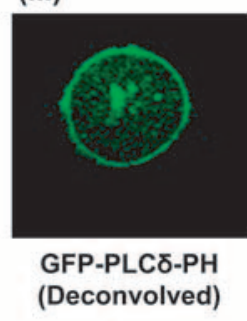

A

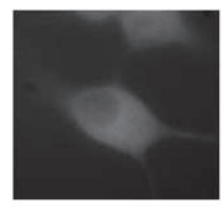

C

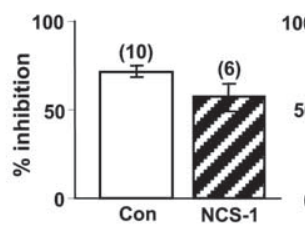

B (i)

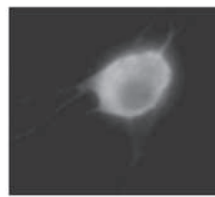

B (ii)

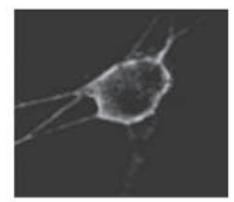

B

Oxotremorine-M

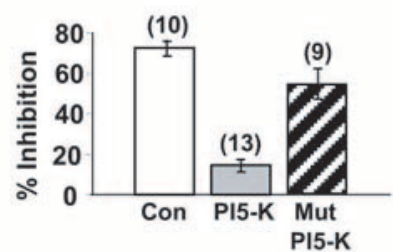

C

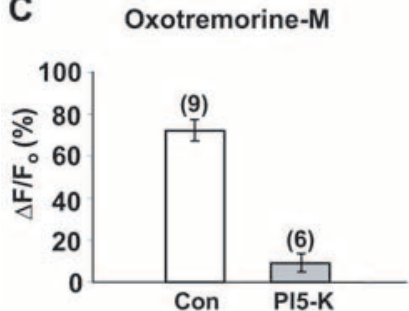

D

\section{Oxotremorine-M}

Wortmannin

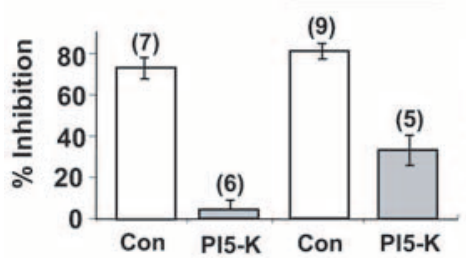

Bradykinin

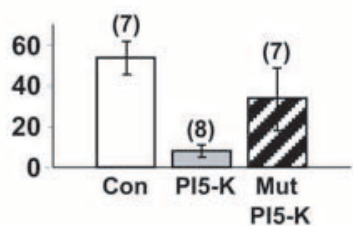

Bradykinin

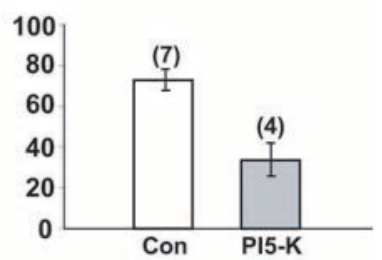

Bradykinin

Wortmannin

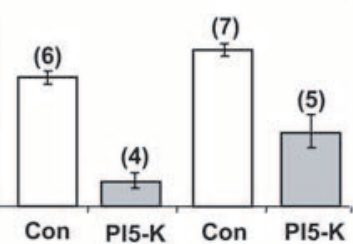

Figure 4. Overexpression of PI5-K reduces M-current inhibition and GFP-PLC $\delta$-PH translocation induced by both oxotremorine- $M$ and bradykinin and is partly reversed by inhibiting phosphatidylinositol-4-kinase with wortmannin. $A$, Sympathetic neuron expressing both a red-tagged (pDSRED) PI5-K (i) and GFP-PLC $\delta$-PH (ii, iii). Aiii shows a deconvolved image of that in $\boldsymbol{i i}$ (see Materials and Methods). $\boldsymbol{B}$, Mean inhibition of the $M$ current (\%) in control (Con), PI5-K, and mutant (Mut) PI5-K overexpressing neurons by 10 $\mu \mathrm{M}$ oxotremorine- $\mathrm{M}$ and $100 \mathrm{~nm}$ bradykinin. The mutant PI5-K was devoid of kinase activity. M-current amplitudes were measured from deactivation tail currents. $C$, Mean rise in cytosolic fluorescence intensity $\left(\Delta F / F_{0} ; \%\right)$ in GFP-PLC $\delta$-PH-expressing cells produced by $10 \mu \mathrm{m}$ oxotremorine-M or $100 \mathrm{~nm}$ bradykinin in control and PI5-K overexpressing cells. $\boldsymbol{D}$, Mean percentage M-current inhibition in control (noninjected) and PI5-K overexpressing neurons in the absence or presence of $15 \mu \mathrm{m}$ wortmannin (added 10 $-15 \mathrm{~min}$ before agonist). Error bars indicate SEM of the number of cells indicated.

et al., 2002).] To avoid desensitization, we used brief pressure applications of $100 \mathrm{~nm}$ bradykinin. $\mathrm{Ca}^{2+}$ signals, although highly variable, were not clearly altered in PI5-K overexpressing cells (controls, $221 \pm 120 \mathrm{nM}, n=5$; PI5-K, $198 \pm 108 \mathrm{nM}, n=6$ ). This suggests that the total amount of $\mathrm{IP}_{3}$ production remained approximately the same, despite the apparent elevation of the initial membrane $\mathrm{PIP}_{2}$ concentration (see below), although we cannot exclude the possibility that the release mechanism might have been partly desensitized at the (presumed) higher resting $\mathrm{IP}_{3}$ concentration.

\section{$\mathbf{F}$}
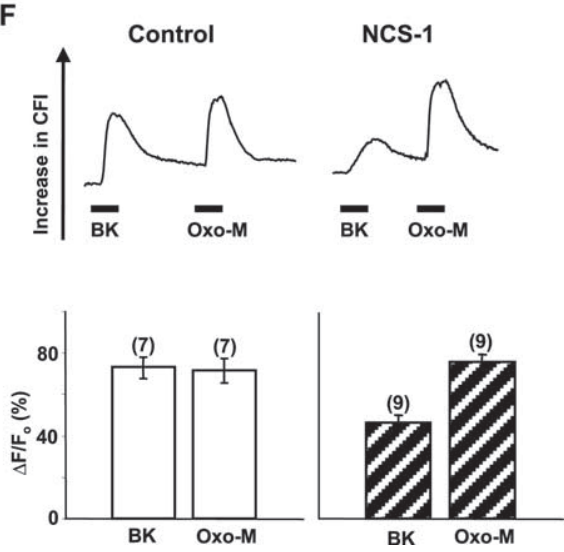

Figure 5. The effects of NCS-1 overexpression in sympathetic neurons. $\boldsymbol{A}, \boldsymbol{B}$, Immunocytochemistry of NCS-1 antibody staining in a noninjected neuron $(\boldsymbol{A})$ and a neuron preinjected intranuclearly $(\boldsymbol{B}) 1 \mathrm{~d}$ previously with NCS-1 CDNA. NCS-1 is endogenously expressed, but staining is enhanced in the NCS-1 CDNA-injected neuron. Bii is a deconvolved image of that in $\mathbf{B i}$, showing that most of the staining is associated with the plasma membrane. $C, D, 0$ verexpression of NCS-1 reduces M-current inhibition by $100 \mathrm{~nm}$ BK (D) but not that produced by $10 \mu \mathrm{m}$ Oxo-M (C).E, Addition of $20 \mu \mathrm{m}$ wortmannin (15 min before) reversed the effect of NCS-1 on BK-induced inhibition. Bars show percentage inhibition of $M$-current measured from deactivation tails. $\boldsymbol{F}$, NCS-1 reduces bradykinin-induced translocation of GFP-PLC $\delta$-PH. Upper records show representative traces of increases in CFI (arbitrary units) in a noninjected neuron (control) and an NCS-1-expressing neuron produced sequentially by BK (100 nм) and 0xo-M (10 $\mu \mathrm{M})$. Lower bar charts show mean values of percentage $\Delta F / F_{0}$ produced by $100 \mathrm{~nm} B K$ and $10 \mu \mathrm{M}$ $0 \times 0-M$ in control and NCS-1 overexpressing neurons. Error bars indicate SEMs of the number of cells indicated.

If the effects of PI5-K overexpression on M-current inhibition result from increased levels of $\mathrm{PIP}_{2}$, these should be reduced or reversed by inhibiting the supply of the substrate phosphatidylinositol-4-phosphate (PIP). To do this, we used 15-20 $\mu \mathrm{M}$ wortmannin, which, at such concentrations, is an effective membrane-permeable inhibitor of PI4-kinase (Nakanishi et al., 1995). As reported previously (Suh and Hille, 2002; Ford et al., 2003), wortmannin itself produced a slow "rundown" of the resting $\mathrm{M}$ current (by $28.7 \pm 4.7 \%$; $n=7$; after $10 \mathrm{~min}$ in $20 \mu \mathrm{M}$ wortmannin) and greatly slowed recovery from oxotremorine$\mathrm{M}$-induced inhibition. It also slowed the recovery of the cytosolic GFP-PLC $\delta$-PH signal; this effect was variable, but, in some neurons, several minutes were required for full recovery. (Attempts to test whether it affected recovery from bradykinin-induced inhibition were frustrated by the very variable duration of bradykinin action in the absence of wortmannin.) However, wortman$\operatorname{nin}(15 \mu \mathrm{M})$ did not significantly affect the fractional inhibition of 
the residual $M$ current by either oxotremorine-M or bradykinin (Fig. 4D). In contrast, it enhanced the (small) inhibition observed in cells overexpressing PI5-K and, hence, partly reversed the effect of the PI5-K (Fig. 4D, filled bars). This provides evidence that the effects of PI5-K overexpression are indeed a result of the increased synthesis of $\mathrm{PIP}_{2}$.

\section{NCS-1 overexpression selectively} reduces the effects of bradykinin NCS-1 is a myristoylated protein that enhances the activity of PI4-kinase (see the Introduction). In PC12 cells, overexpression of NCS-1 has been reported to increase cellular levels of PIP and PIP $_{2}$ to enhance $\mathrm{IP}_{3}$ production and $\mathrm{Ca}^{2+}$ release by UTP and to increase $\mathrm{Ca}^{2+}$ release by bradykinin (Koizumi et al., 2002; Rajebhosale et al., 2003). In the present experiments, previous intranuclear injection of an NCS-1 cDNA plasmid increased levels of NCS-1 protein in sympathetic neurons as determined by immunofluorescent antibody staining $2 \mathrm{~d}$ later (Fig. $5 A, B$ ). Deconvolution imaging indicated that much of the increased staining was in, or near, the plasma membrane (Fig. 5Bii).

M-current amplitudes in NCS-1 overexpressing neurons were not significantly different from those in uninjected neurons or in sham (GFP-plasmid)-injected neurons. Mean amplitudes were as follows: controls, $129 \pm 27 \mathrm{pA}(n=11)$; NCS- 1 , $105 \pm 12 \mathrm{pA}(n=9) ; \mathrm{GFP}, 122 \pm 18 \mathrm{pA}$ $(n=9)$. There was also no significant change in the inhibition of $\mathrm{M}$ current produced by $10 \mu \mathrm{M}$ oxotremorine-M (Fig. $5 C)$. However, the inhibition produced by $100 \mathrm{~nm}$ bradykinin was reduced from $43 \pm$ $9.0 \%(n=5)$ to $14 \pm 4.4 \%(n=6)$ (Fig.

$5 D)$. This effect was reversed by the PI4-K inhibitor wortmannin $(20 \mu \mathrm{M})$ (Fig. 5E).

NCS-1 overexpression also did not affect the resting membrane:cytosol distribution of GFP-PLC $\delta$-PH. However, as with M-current inhibition, NCS-1 selectively reduced the increase in cytosolic fluorescence produced by bradykinin (Fig. $5 F$ ).

A component, at least, of the inhibition of $\mathrm{M}$ current by bradykinin appears to be mediated by $\mathrm{Ca}^{2+}$ release (see the Introduction). Because NCS-1 is a $\mathrm{Ca}^{2+}$-binding protein (Schaad et al., 1996), the reduction of bradykinin-induced inhibition in NCS-1 overexpressing neurons in Figure $5 D$ might have resulted from increased buffering of intracellular $\mathrm{Ca}^{2+}$. This was difficult to assess directly because of the small amplitude and variability of the bradykinin-induced $\mathrm{Ca}^{2+}$ signals (see above). Instead, we tested for changes in buffering capacity by comparing the integral of the $\mathrm{Ca}^{2+}$ current evoked by $200 \mathrm{~ms}$ depolarizing voltage steps to 0 from $-70 \mathrm{mV}$ with the peak rise in intracellular free $\left[\mathrm{Ca}^{2+}\right]$ recorded using fura-2 as described by Wanaverbecq et al. (2003). From this, the $\mathrm{Ca}^{2+}$-binding ratio may be calculated as $\kappa=$ $\Delta\left[\mathrm{Ca}^{2+}\right]_{\text {bound }} / \Delta\left[\mathrm{Ca}^{2+}\right]_{\mathrm{i}}=\left(\Delta\left[\mathrm{Ca}^{2+}\right]_{\text {total }}-\Delta\left[\mathrm{Ca}^{2+}\right]_{\mathrm{i}}\right) / \Delta\left[\mathrm{Ca}^{2+}\right]_{\mathrm{I}}$, where $\Delta\left[\mathrm{Ca}^{2+}\right]_{\mathrm{i}}$ is the increase in free cytosolic $\mathrm{Ca}^{2+}$ measured with inhibited the current.
B
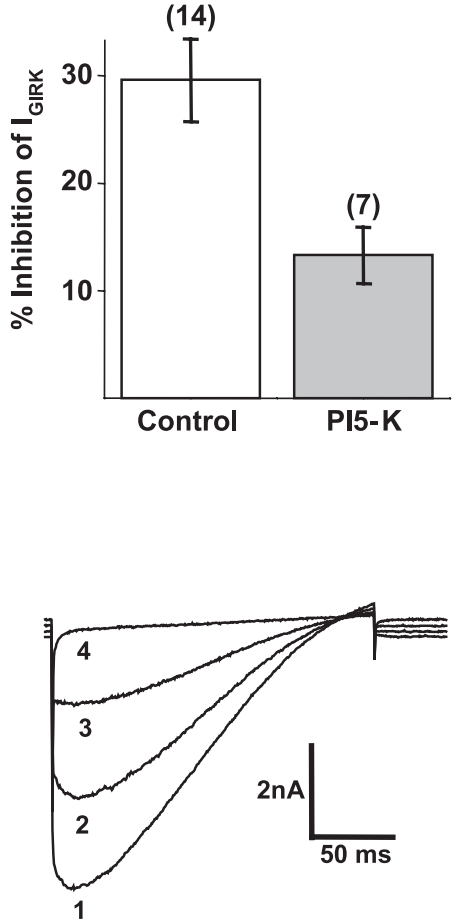

Figure 6. Activation and inhibition of GIRK by 0x0-M and reduction of inhibition after overexpression of PI5-K. A, Representative time plot of currents activated by $10 \mu \mathrm{m} 0 \times 0-\mathrm{M}$ in individual control and PI5-K-overexpressing neurons. Currents were

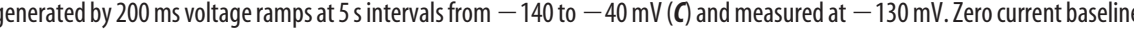
fells indicated. C, Muscarinic inhibition of GIRK preactivated by coexpression of G-protein $\beta \gamma$ subunits. Currents were preacti-

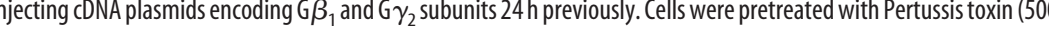
the time plot. 0xo-M $(10 \mu \mathrm{m})$ inhibited the current without previous activation (compare with $\boldsymbol{A}) . \mathrm{Ba}^{2+}(0.1$ and $1 \mathrm{~mm})$ further

fura-2, and $\Delta\left[\mathrm{Ca}^{2+}\right]_{\text {total }}$ is the total $\mathrm{Ca}^{2+}$ entry calculated from the clamp current. The baseline for the latter was set using $1 \mathrm{mM} \mathrm{Co}^{2+}$ to suppress the $\mathrm{Ca}^{2+}$ current. NCS-1-expressing cells were identified using pDSRed instead of GFP to prevent interference with the fura-2 signals. NCS-1 had no significant effect on the relationship between $\mathrm{Ca}^{2+}$ entry and fura- 2 fluorescence or on the mean calculated binding ratio $\kappa$ deduced therefrom (control, $650 \pm 140, n=6$; NCS-1, $830 \pm 180, n=7$ ). Also, NCS-1 had no effect on the resting levels of $\left[\mathrm{Ca}^{2+}\right]_{\mathrm{i}}$ as measured by fura-2 fluorescence (controls, $231 \pm 12 \mathrm{nM}$, $n=18$; NCS-1, $210 \pm 12 \mathrm{nM}, n=10$; GFP, $224 \pm 25 \mathrm{nM}, n=8)$. Thus, the effects of NCS- 1 are unlikely to be the result of any appreciable increase in $\mathrm{Ca}^{2+}$ buffering.

\section{Effect of PI5-K overexpression on inhibition of GIRK currents}

GIRK currents were generated in these neurons by intranuclear coinjection of plasmids encoding GIRK1 and GIRK2 subunits (Kv3.1 and Kv3.2) along with a marker plasmid encoding GFP, as described previously (Ruiz-Velasco \& Ikeda, 1998; FernandezFernandez et al., 1999; Filippov et al., 2004). Currents were generated by voltage ramps (from -140 to $-40 \mathrm{mV}$ ) and identified 
A

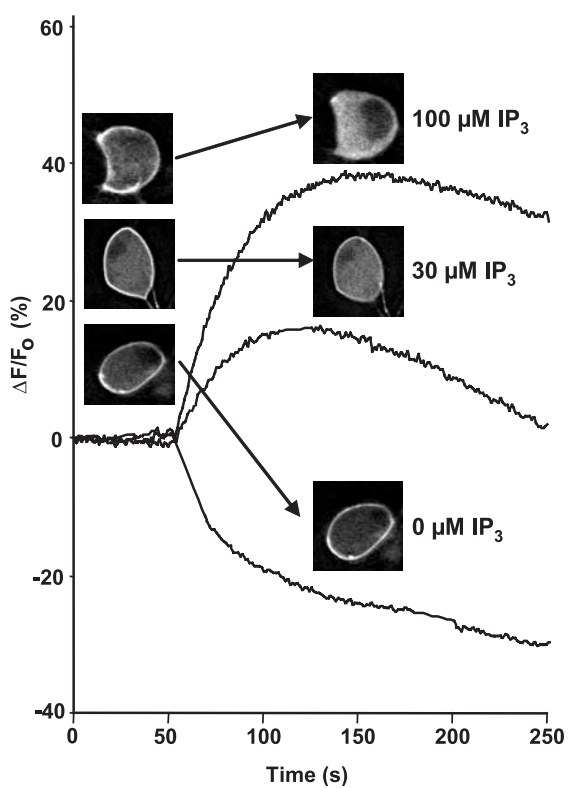

B

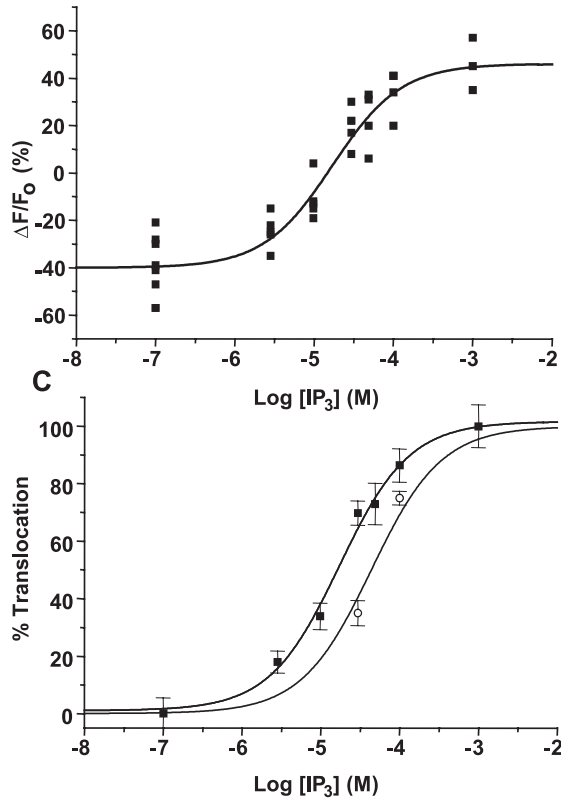

by $\sim 57 \%$, from $29.6 \pm 3.3 \%(n=12)$ to $12.8 \pm 2.5 \%(n=4)$ (Fig. $6 B)$. We also tested the effect of bradykinin (100 nM), but this agonist failed to inhibit the GIRK current in any of six cells tested.

Quantification of membrane $\mathrm{PIP}_{2}$ levels from GFP-PLC $\delta$-PH measurements

The PLC $\delta$-PH peptide binds to both $\mathrm{PIP}_{2}$ and $\mathrm{IP}_{3}$ (Garcia et al., 1995; Lemmon et al., 1995). Hence, translocation from membrane to cytosol during $\mathrm{PIP}_{2}$ hydrolysis reflects (to differing extents) both the reduction of membrane $\left[\mathrm{PIP}_{2}\right]$ and the rise in cytosolic $\left[\mathrm{IP}_{3}\right]$ and indeed has been used as an index of both changes (Stauffer et al., 1998; Varnai and Balla, 1998; Hirose et al., 1999; Van der Wal et al., 2001; Nahorski et al., 2003). Notwithstanding, it is possible (in principle) to estimate individual changes in $\left[\mathrm{PIP}_{2}\right]$ and $\left[\mathrm{IP}_{3}\right]$ from translocation measurements (Xu et al., 2003). Because the inhibition of $\mathrm{M}$ current by oxotremorine- $\mathrm{M}$ is suggested to result from changes in $\left[\mathrm{PIP}_{2}\right]$ rather than $\left[\mathrm{IP}_{3}\right]$ (see the Introduction), we attempted to use our measurements of GFP-PLC $\delta$-PH fluorescence to calculate both the resting concentrations of membrane $\left[\mathrm{PIP}_{2}\right]$ and the changes in these concentrations after application of oxotremorine-M. For this, we used a different approach to the "model cell” approach used by Xu et al. (2003), based on (so far as possible) data obtained directly from our experiments on ganglion cells.

Resting membrane $\left[\mathrm{PIP}_{2}\right]$ and the effect of PI5-K overexpression

from their current-voltage relationship and inhibition by $100 \mu \mathrm{M}$ to $1 \mathrm{mM} \mathrm{Ba}^{2+}$ (Filippov et al., 2004) (Fig. 6C).

Oxotremorine-M produced a biphasic effect: generation of an inward current, followed by a decline toward baseline (Fig. $6 A, B)$. We attribute this to an initial activation of the GIRK current via $\mathrm{M}_{2}$-mAChRs (Fernandez-Fernandez et al., 1999) with subsequent inhibition via $\mathrm{M}_{1}-\mathrm{mAChRs}$ (Hill and Peralta, 2001). That the latter effect was attributable to inhibition of the $\mathrm{M}_{2}$ activated current (rather than desensitization) is confirmed by the fact that oxotremorine-M also inhibited GIRK currents preactivated by stimulating $\alpha 2$-adrenoceptors with $10 \mu \mathrm{M}$ norepinephrine (data not shown) or by expressing G-protein $\beta_{1} \gamma_{2}$ subunits (Fig. 6C) (Filippov et al., 2004). In the latter case, inhibition was measured in the presence of Pertussis toxin (to prevent $\mathrm{M}_{2}-\mathrm{mAChR}$ activation). Oxotremorine- $\mathrm{M}$ produced a concentration-dependent inhibition of the preactivated current of up to $60 \%$ of that inhibited by $1 \mathrm{~mm} \mathrm{Ba}^{2+}$, with an $\mathrm{IC}_{50}$ value of $1.16 \pm 0.14 \mu \mathrm{M}$ (pooled data from four cells), quite comparable with that for M-current inhibition (compare with Fig. 3).

In PI5-K overexpressing neurons, the initial $\left(\mathrm{M}_{2}\right)$ activation of the GIRK current noted in Figure 6 was unchanged, but the subsequent $\left(\mathrm{M}_{1}\right)$ inhibitory effect was strongly reduced compared with that in control cells (Fig. 6A). When measured $30 \mathrm{~s}$ after the peak of the $\mathrm{M}_{2}$-activated current, inhibition was reduced
We estimated resting membrane $\left[\mathrm{PIP}_{2}\right]\left(\left[\mathrm{PIP}_{2}\right]_{\text {Rest }}\right)$ using an intracellular $\mathrm{IP}_{3}$ competition assay. Starting from the situation in which most of the GFP-PLC $\delta$-PH fluorescence is localized to the plasma membrane (where it is presumably bound to phosphatidylinositides, including $\mathrm{PIP}_{2}$ ), we patched neurons in open-tip configuration with pipettes containing different concentrations of $\mathrm{IP}_{3}$ and recorded the rise in cytosolic fluorescence (Fig. 7A). To "freeze" $\mathrm{PIP}_{2}$ concentrations at their prepatch level, we used an EGTA-buffered $\mathrm{Ca}^{2+}$-free intracellular solution, because $\mathrm{Ca}^{2+}$ is required for PLC function (Rhee, 2001).

In the absence of intrapipette $\mathrm{IP}_{3}$, cytosolic fluorescence declined on breaking through with the pipette. This may be attributed to washout not only of resting cytosolic $\mathrm{IP}_{3}$ but also of any other diffusible molecules with polar groups that might bind GFP-PLC $\delta$-PH, plus any free (unbound) GFP-PLC $\delta$-PH. [There may also be some increase in the available "free space" (see below) as a result of disruption of cytoplasmic organelles by whole-cell patching.] With increasing concentrations of $\mathrm{IP}_{3}$ added to the pipette solution, there was a progressively increasing fluorescence above this zero- $\mathrm{IP}_{3}$ baseline (Fig. $7 \mathrm{~B}$ ). After baseline subtraction and scaling (Fig. 7C), the concentration-response curve yielded a mean $\mathrm{EC}_{50}$ value of $16 \pm 1.2$ $\mu \mathrm{M}$. We then repeated these experiments in cells overexpress- 
ing PI5-K. For these tests, we used two concentrations of $\mathrm{IP}_{3}$, 30 and $100 \mu \mathrm{M}$. These concentrations clearly produced less translocation than in the control cells, giving an estimated $\mathrm{EC}_{50}$ value of $\sim 43 \mu \mathrm{M}$ from the transposed concentrationresponse curve (Fig. $7 C$, filled circles).

With a small correction for intracellular $\mathrm{IP}_{3}$ breakdown (estimated at $<5 \%$ at $3 \mu \mathrm{M}$ intrapipette $\left[\mathrm{IP}_{3}\right],<1 \%$ at $>10 \mu \mathrm{M}$ ) (see supplemental material 1, available at www.jneurosci.org), the data in Figure $7 C$ yielded the following values for the $\mathrm{IP}_{3} \mathrm{EC}_{50}$ value (means, with lower and upper 95\% confidence limits) (in $\mu \mathrm{M})$ : controls, 16.1 (11.9 - 23.5); + PI5-K, 42.7 (25.7 - 70.9). These results are broadly similar to those obtained by Van der Wal et al. (2001) in neuroblastoma cells using flash photolysis of caged $\mathrm{IP}_{3}$, in which $\mathrm{IP}_{3}$ concentrations between 10 and $100 \mu \mathrm{M}$ were required to produce substantial translocation. The requirements for such high concentrations may seem surprising, because the dissociation equilibrium constant for $\mathrm{IP}_{3}$ binding to PLC $\delta$-PH has been reported to be $\sim 0.1-0.2 \mu \mathrm{M}$, as opposed to $\sim 2 \mu \mathrm{M}$ for binding to $\mathrm{PIP}_{2}$ (Lemmon et al., 1995; Hirose et al., 1999). The reason is that, clearly, the resting concentration of $\mathrm{PIP}_{2}$ (and other potential GFP-PLC $\delta$-PH-binding phosphoinositides) in the membrane must be even higher.

The other principal PLC $\delta$-PH-binding phosphoinositide is phosphatidylinositol-4-phosphate, which has a binding constant of $\sim 7 \mu \mathrm{M}$ (Garcia et al., 1995) and is present at $\sim 80 \%$ of the concentration of $\mathrm{PIP}_{2}$ in neuroblastoma cell membranes (Willars et al., 1998) and $\sim 60 \%$ in human erythrocyte membranes (Ferrell and Huestis, 1984). We ignored phosphatidylinositol (PI) because, even if present in excess over PIP 2 (Willars et al., 1998; Xu et al., 2003) (but see Ferrell and Huestis, 1984), phosphatidylcholine/phosphatidylserine (PC/PS) liposomes doped with 1\% PI show very little extra binding of PLC $\delta$ - $\mathrm{PH}$ over PC/PS liposomes alone [Garcia et al. (1995), their Fig. 2]. We can also ignore other double-phosphorylated and triple-phosphorylated PIs, because, even though these bind PLC $\delta$-PH with comparable affinity to $\mathrm{PI}(4,5) \mathrm{P}$ (Garcia et al., 1995), their sum concentration is $<1 \%$ of that of $\mathrm{PI}(4,5) \mathrm{P}_{2}$ (Vanhaesebroeck et al., 2001).

The proportion of GFP-PLC $\delta$-PH bound to $\operatorname{IP}_{3}\left(P_{\mathrm{IP} 3}\right)$ is then given by the following standard competitive binding equation:

$$
P_{\mathrm{IP} 3}=C_{\mathrm{IP} 3} /\left(1+C_{\mathrm{PIP} 2}+C_{\mathrm{PIP}}+C_{\mathrm{IP} 3}\right),
$$

where $C_{\mathrm{IP} 3}=\left[\mathrm{IP}_{3}\right] / K_{\mathrm{IP} 3} C_{\mathrm{PIP} 2}=\left[\mathrm{PIP}_{2}\right] / K_{\mathrm{PIP} 2}$, and $C_{\mathrm{PIP}}=[\mathrm{PIP}] /$ $K_{\mathrm{PIP}}$, and $K_{\mathrm{IP} 3}, K_{\mathrm{PIP} 2}$, and $K_{\mathrm{PIP}}$ are the dissociation equilibrium constants for GFP-PLC $\delta$-PH to $\mathrm{IP}_{3}, \mathrm{PIP}_{2}$, and PIP, respectively. At the $\mathrm{EC}_{50}$ value for the $\mathrm{IP}_{3}$-induced rise in cytosolic fluorescence (when $P_{1 \mathrm{P} 3}=0.5$ ), this simplifies to the following:

$$
C_{\mathrm{PIP} 2}+C_{\mathrm{PIP}}=C_{\mathrm{IP} 3}-1 .
$$

This was solved for $\left[\mathrm{PIP}_{2}\right]$ by setting $K_{\mathrm{IP} 3}=0.1 \mu \mathrm{M}, K_{\mathrm{PIP} 2}=2 \mu \mathrm{M}$, $K_{\mathrm{PIP}}=7 \mu \mathrm{M}$, and $[\mathrm{PIP}]=0.8\left[\mathrm{PIP}_{2}\right]$ (Table 1$)$. The $\mathrm{EC}_{50}$ values for $\mathrm{IP}_{3}$-induced GFP-PLC $\delta$-PH displacement in Figure 7 then yielded the following estimates for $\left[\mathrm{PIP}_{2}\right]$ (means with upper and lower 95\% confidence limits): controls, $261 \mu \mathrm{M}(192-381)$; +PI5-K, $693 \mu \mathrm{M}$ (417-1153).

These estimates of the initial (resting) levels of $\mathrm{PIP}_{2}$ assume that the instillation of $\mathrm{IP}_{3}$ does not significantly change the level of $\mathrm{PIP}_{2}$ in the membrane during the time required for the fluorescence measurements. This seems a reasonable assumption, because the slope of the $\left[\mathrm{IP}_{3}\right] /$ translocation curve in Figure $7 C$ was near unity, whereas elevation of membrane $\mathrm{PIP}_{2}$ would be expected to produce a progressive reduction in translocation and hence flattening of the curve. The absolute

\begin{tabular}{|c|c|c|}
\hline Parameter & Value & Source \\
\hline$K_{\mathrm{IP} 3}$ & $0.1 \mu \mathrm{M}$ & Hirose et al. (1999) \\
\hline$K_{\mathrm{PIP} 2}$ & $2 \mu \mathrm{M}$ & Hirose et al. (1999) \\
\hline$K_{\text {PIP }}$ & $7 \mu \mathrm{M}$ & Garcia et al. (1995) \\
\hline CMVR & 83 & Figure $8 A$; cell radius, $10.1 \mu \mathrm{M}$ \\
\hline $\left.\mathrm{PIP}_{2}\right]_{\text {Rest }}$ & $261 \mu \mathrm{M}$ & Figure 7 , Equation 2 \\
\hline$\left[\mathrm{PIP}_{2}\right]_{\text {Rest }}(+\mathrm{PI} 5-\mathrm{K})$ & $693 \mu \mathrm{M}$ & Figure $7 C$, Equation 2 \\
\hline$[P I P]_{\text {Rest }}$ & $208 \mu \mathrm{M}$ & $\begin{array}{l}\text { Figure } 7 C ;[\mathrm{PIP}]=0.8 *\left[\mathrm{PIP}_{2}\right] \\
\quad \text { (Willars et al., 1998) }\end{array}$ \\
\hline$[\mathrm{PIP}]_{\text {Rest }}(+\mathrm{PI} 5-\mathrm{K})$ & $554 \mu \mathrm{M}$ & Proportionate to $\left[\mathrm{PIP}_{2}\right]_{\text {Rest }}(+\mathrm{PI} 5-\mathrm{K})$ \\
\hline$\left[\mathrm{IP}_{3}\right]_{\text {Rest }}$ & $0.16 \mu \mathrm{m}$ & Fink et al. (1999) \\
\hline$\left[\mathrm{IP}_{3}\right]_{\text {Rest }}(+\mathrm{PI} 5-\mathrm{K})$ & $0.42 \mu \mathrm{M}$ & Proportionate to $\left[\mathrm{PIP}_{2}\right]_{\text {Rest }}(+\mathrm{PI} 5-\mathrm{K})$ \\
\hline $\begin{array}{l}\text { Fractional GFP-PLC } \delta \text {-PH translocation } \\
\qquad\left(\Delta F / F_{0}\right)\end{array}$ & 0.86 & $\begin{array}{l}\text { Figure } 7 B\left(\Delta F / F_{0}=0.86 \text { at maximal }\right. \\
\left.\qquad\left[\mathrm{IP}_{3}\right]\right)\end{array}$ \\
\hline \multicolumn{3}{|l|}{ M-channel availability } \\
\hline$K_{\mathrm{M}}$ & $87.2 \mu \mathrm{M}\left[\mathrm{PIP}_{2}\right]$ & Zhang et al. (2003) \\
\hline$n_{\mathrm{H}}$ & 1.35 & Zhang et al. (2003) \\
\hline
\end{tabular}

\section{Table 1. Numerical values used in Equations $1-5$ and Figures $8 B$ and 9}

values will also depend critically on the ratio of the binding constants, but the proportionate change on overexpressing PI5-K would be unchanged.

We also used the intracellular $\mathrm{IP}_{3}$ displacement assay to assess the effect of NCS-1 on membrane [PIP 2 . For this, we used a single $(30 \mu \mathrm{M})$ concentration of intracellular $\mathrm{IP}_{3}$. Because NCS-1 is a $\mathrm{Ca}^{2+}$-binding protein, we measured the $\mathrm{IP}_{3}$-induced rise in cytosolic fluorescence using intracellular solutions containing 0 and $200 \mathrm{nM}$ buffered $\left[\mathrm{Ca}^{2+}\right]$. Mean values $( \pm \mathrm{SEM})$ for $\Delta F / F_{0}$ (\%) from the $0\left[\mathrm{IP}_{3}\right]$ baseline were as follows: $0 \mathrm{Ca}^{2+}-\mathrm{NCS}-1$, $59.8 \pm 3.8(n=5) ; 0\left[\mathrm{Ca}^{2+}\right]$ plus NCS-1, $48.8 \pm 1.8(n=6) ; 200$ $\mathrm{nM}\left[\mathrm{Ca}^{2+}\right]-\mathrm{NCS}-1,57.3 \pm 2.0(n=6) ; 200 \mathrm{nM}\left[\mathrm{Ca}^{2+}\right]$ plus NCS-1, $50.3 \pm 2.3$. None of these values were significantly different from the control values at $30 \mu \mathrm{M}$ in Fig. 7. Thus, although there might have been some reduction of $\mathrm{IP}_{3}$ displacement fluorescence in NCS-1 overexpressing cells (which was not dependent on the absence or presence of $200 \mathrm{~nm}\left[\mathrm{Ca}^{2+}\right]$ ), the effect of NCS-1 was much less than that of PI5-K overexpression (in which the corresponding $\Delta F / F_{\mathrm{o}}$ at $30 \mu \mathrm{M}\left[\mathrm{IP}_{3}\right]$ was reduced to $30.1 \pm 3.8 \%)$. At best, we estimate a maximum increase in resting membrane $\left[\mathrm{PIP}_{2}\right]$ of $\sim 100-150 \mu \mathrm{M}$, in line with the data of Koizumi et al. (2002) and Rajebhosale et al. (2003) suggesting rises of 50 and $25 \%$, respectively.

We emphasize that these calculated $\mathrm{PIP}_{2}$ concentrations are the effective concentrations in the plasma membrane as "seen" by the GFP-PLC $\delta$-PH tag. Assuming they refer only to $\mathrm{PIP}_{2}$ in the inner (5-nm-thick) leaflet of the membrane, they equate to a density of 783 molecules of $\mathrm{PIP}_{2} / \mu \mathrm{m}^{2}$ membrane area if arranged as a monolayer, rising to $2079 / \mu \mathrm{m}^{2}$ after overexpressing PI5-K. These values are substantially less than previous estimates for neuroblastoma cells $\left(4000 / \mu \mathrm{m}^{2}\right.$ ) (Xu et al., 2003) based on measurements of total membrane phospholipid. In these measurements, $\mathrm{PIP}_{2}$ comprised $0.43 \%$ of total membrane phospholipid, whereas our measurements imply correspondingly lower values of $\sim 0.08 \%$, rising to $0.22 \%$ with PI5-K. However, note the following: (1) the calculations of $\mathrm{Xu}$ et al. (2003) do not appear to allow for the area occupied by membrane protein, and (2) GFP-PLC $\delta$-PH only bound to the plasma membrane (Fig. $1 A$ ) not the intracellular membranes included in biochemical assays.

\section{Changes in fluorescence after $\mathrm{PIP}_{2}$ hydrolysis}

Stimulation of muscarinic acetylcholine receptors accelerates $\mathrm{PIP}_{2}$ hydrolysis and produces a fall in membrane $\left[\mathrm{PIP}_{2}\right]$, with an equiva- 
A

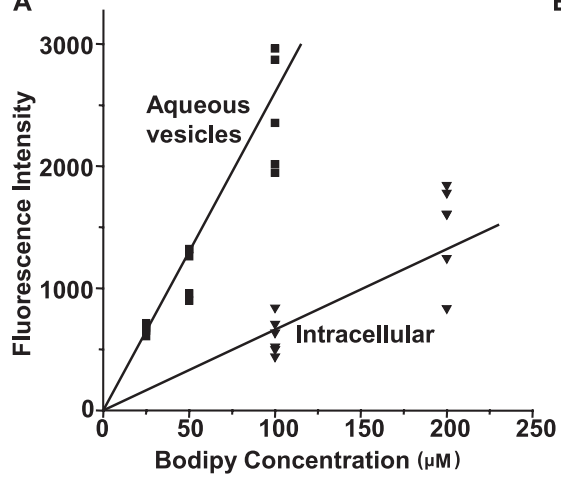

B

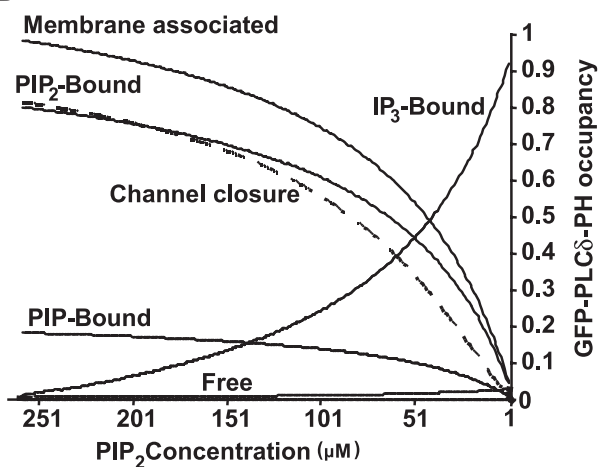

Figure 8. $\quad \boldsymbol{A}$, Determination of the free cytosolic volume. Graphs show the mean fluorescence intensity (ordinates) after the dispersion of different concentrations of a fluorescent low-molecular-weight compound (BODIPY-FL) in aqueous vesicles (squares) and mean cytosolic intensity of sympathetic neurons whole-cell patched with electrodes containing the same fluorescent compound (triangles) (see Materials and Methods). Mean slopes (fluorescence intensity per micromolar concentration $[B O D I P Y]) \pm$ SEM were as follows: aqueous vesicles, $26 \pm 0.9$; intracellular, $6.6 \pm 0.66$. The ratio of the slopes provides a measure of the free cytosolic space available to BODIPY, from which cytosolic concentration of $\mathrm{IP}_{3}$ generated by $\mathrm{PIP}_{2}$ hydrolysis could be estimated (see Results). $\boldsymbol{B}$, Changes in distribution of GFP-PLC $\delta$-PH between membrane and cytosol with progressive hydrolysis of PIP ${ }_{2}$, calculated from Equations 3-7, for a sympathetic neuron with a diameter of $20 \mu \mathrm{M}$, an initial membrane PIP ${ }_{2}$ concentration of $261 \mu \mathrm{M}$, an effective CMVR of 83 , and binding constants of 0.1 and $2 \mu \mathrm{m}$ for $\mathrm{IP}_{3}$ and PIP ${ }_{2}$, respectively (Table 1). The dashed line shows how the fractional $\mathrm{M}$-channel availability would be expected to change during $\mathrm{PIP}_{2}$ hydrolysis, as calculated from the data in the study by Zhang et al. (2003).

lent fall in [PIP], presumably through conversion to PIP $_{2}$ (Willars et al., 1998). Knowing the initial membrane concentrations of PIP $_{2}$ and PIP, one can calculate the amount of $\mathrm{IP}_{3}$ formed as it is hydrolyzed and its concentration in the cytosol from the cytosolic/membrane volume ratio (CMVR) as follows:

$$
\left[\mathrm{IP}_{3}\right]=\frac{1.8^{\star} \Delta\left[\mathrm{PIP}_{2}\right]}{\mathrm{CMVR}}+\left[\mathrm{IP}_{3}\right]_{\mathrm{Rest}}
$$

where $\Delta\left[\mathrm{PIP}_{2}\right]=\left[\mathrm{PIP}_{2}\right]_{\text {Rest }}-\left[\mathrm{PIP}_{2}\right]$ (the multiplicand 1.8 reflects the additional formation of $\mathrm{IP}_{3}$ by PIP through conversion to $\mathrm{PIP}_{2}$ ). The proportions of GFP-PLC $\delta$-PH remaining in the membrane bound to $\mathrm{PIP}_{2}$ and PIP as the hydrolysis proceeds is then given by the following:

$$
P_{\mathrm{PIP} 2}=\frac{\left[\mathrm{PIP}_{2}\right]}{K_{\mathrm{PIP} 2}\left[1+\frac{\left[\mathrm{IP}_{3}\right]}{K_{\mathrm{IP} 3}}+\frac{0.8^{*}\left[\mathrm{PIP}_{2}\right]}{K_{\mathrm{PIP}}}\right]+\left[\mathrm{PIP}_{2}\right]}
$$

and

$$
P_{\mathrm{PIP}}=\frac{0.8^{*}\left[\mathrm{PIP}_{2}\right]}{K_{\mathrm{IP} 3}\left[1+\frac{\left[\mathrm{PIP}_{2}\right]}{K_{\mathrm{PIP} 2}}+\frac{\left[\mathrm{IP}_{3}\right]}{K_{\mathrm{IP} 3}}\right]+0.8^{*}\left[\mathrm{PIP}_{2}\right]} .
$$

Of the GFP-PLC $\delta$-PH that accumulates in the cytosol, most is bound to $\mathrm{IP}_{3}$, but some is free. These proportions are given by the following:

$$
P_{\mathrm{IP} 3}=\frac{\left[\mathrm{IP}_{3}\right]}{K_{\mathrm{IP} 3}\left[1+\frac{\left[\mathrm{PIP}_{2}\right]}{K_{\mathrm{PIP} 2}}+\frac{0.8^{\star}\left[\mathrm{PIP}_{2}\right]}{K_{\mathrm{PIP}}}\right]+\left[\mathrm{IP}_{3}\right]}
$$

and

$$
P_{\text {Free }}=1-P_{\mathrm{IP} 3}-P_{\mathrm{PIP} 2}-P_{\mathrm{PIP}} .
$$

To solve these equations, we need to determine the following: (1) the cell size and cell volume available to $\mathrm{IP}_{3}$ to calculate CMVR
(Eq. 3) and (2) the relationship between the measured increase in cytosolic fluorescence $\left(\Delta F / F_{0}\right)$ and proportion of total GFP-PLC $\delta$-PH in the cytosol (i.e., the fractional translocation of GFP-PLC $\delta$-PH from membrane to cytosol).

\section{Cell volume and cytoplasmic:membrane volume ratio}

We estimated the total cell volume from three-dimensional reconstructions of calcein-loaded neurons (see Materials and Methods). In a sample of five cells, the mean volume was $4289 \pm 382 \mathrm{fl}(\mathrm{SEM})$. This would correspond to a spherical cell of $10.1 \mu \mathrm{m}$ radius and would yield a CMVR of $\sim 330$, assuming a membrane thickness of $10 \mathrm{~nm}$. However, not all of the intracellular space will be available to $\mathrm{IP}_{3}$. To estimate the volume of distribution of $\mathrm{IP}_{3}$, we compared the mean overall cell fluorescence in neurons patched with pipettes containing a low molecular weight hydrophilic fluorescent marker (BODIPY) with that in equivalent-sized aqueous vesicles (Fig. 8A) (see Materials and Methods). Intracellular fluorescence was clearly less than that expected from the vesicular fluorescence, suggesting that the volume of distribution of BODIPY was $\sim 25 \%$ of the total intracellular volume. Assuming that the volume of distribution of $\mathrm{IP}_{3}$ is similar to that of BODIPY, the effective CMVR in Equation 1 is then 83. This implies that, in a normal neuron (with membrane $\left[\mathrm{PIP}_{2}\right]$ of

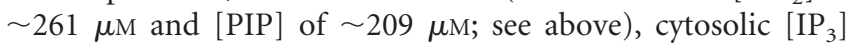
would rise to $5.82 \mu \mathrm{M}$ from an assumed baseline value of $0.16 \mu \mathrm{M}$ (Fink et al., 1999) when all PIP 2 and PIP (after conversion to $\mathrm{PIP}_{2}$ ) is hydrolyzed. Again, this is not unreasonable, because this does not allow for any hydrolysis of $\mathrm{IP}_{3}$. There have been no direct measurements in sympathetic neurons; however, Fink et al. (1999) estimated a value of $\sim 2 \mu \mathrm{M}$ in neuroblastoma cells after strong stimulation with bradykinin. However, these cells are appreciably larger than sympathetic neurons (giving a larger CMVR), and bradykinin is unlikely to produce complete hydrolysis of $\mathrm{PIP}_{2}$ (see below).

\section{Relationship between cytosolic fluorescence increase and membrane-to-cytosol GFP-PLC $\boldsymbol{\delta}$-PH translocation}

We assume that the increase in cytosolic fluorescence $\Delta F / F_{0}$ produced by saturating concentrations of intracellular $\mathrm{IP}_{3}$ reflects total membrane-to-cytosol translocation of GFP-PLC $\delta$-PH. This value ( $+86 \%$ from the zero- $\mathrm{IP}_{3}$ baseline) (Fig. $7 B$ ) is greater than that following maximum concentrations of oxotremorine-M $(+60 \%)$ (Fig. 3), suggesting that oxotremorine-M does not produce full GFP-PLC $\delta$-PH translocation. We rechecked this by superimposing a breakthrough with a pipette filled with a saturating $(100 \mu \mathrm{M})$ concentration of $\mathrm{IP}_{3}$ at the peak of the response to a single application of $10 \mu \mathrm{M}$ oxotremorine-M. This produced an additional increase in cytosolic fluorescence from which (after baseline correction) we calculated that oxotremorine-M produced $77.4 \pm 2.5 \%$ ( $n=5$ cells $)$ of the maximum translocation produced by $\mathrm{IP}_{3}$ (in reasonable agreement with the difference in maximum values of $\Delta F / F_{0}$ for $\mathrm{IP}_{3}$ and oxotremorine-M recorded separately). Accordingly, we took the $86 \%\left(\Delta F / F_{0}\right)_{\max }$ for intra- 
cellular $\mathrm{IP}_{3}$ as representing $100 \%$ translocation and divided agonist-induced $\Delta F / F_{0}$ by 0.86 to obtain fractional translocation.

\section{Distribution of the fluorescence signal and calculation of $\left[\mathrm{PIP}_{2}\right]$}

Starting from the estimated mean values for $\left[\mathrm{PIP}_{2}\right]_{\text {Rest }}$ as deduced from the $\mathrm{IP}_{3}$ displacement results $(261 \mu \mathrm{M}$ in controls and $679 \mu \mathrm{M}$ with PI5-K), we solved Equations 3-7 numerically for diminishing values of $\left[\mathrm{PIP}_{2}\right]$, because $\mathrm{PIP}_{2}$ is hydrolyzed. Figure $8 B$ shows the results of such calculations for normal cells with $261 \mu \mathrm{M}$ $\left[\mathrm{PIP}_{2}\right]_{\text {Rest }}$, using numerical values listed in Table 1 . From this (and the equivalent readout for PI5-K overexpressing cells), we determined the concentration of $\left[\mathrm{PIP}_{2}\right]$ that corresponded to the fractional translocation calculated from the observed cytosolic fluorescence $\left[\left(\Delta F / F_{0}\right) / 0.86\right.$; see above $]$. $\left[\mathrm{PIP}_{2}\right]$ can also be solved numerically from an expanded version of Equation 1, if the small fraction of free cytoplasmic GFP-PLC $\delta$-PH is ignored (see supplemental material 2, available at www.jneurosci.org).

\section{Relationship between fluorescence change and M-current inhibition}

First, we determined how far the close relationship between the increase in cytosolic fluorescence and M-current inhibition produced by increasing concentrations of oxotremorine-M (Fig. 3) might be expected from the " $\mathrm{PIP}_{2}$-gating" hypothesis. Taking the values of $\left[\mathrm{PIP}_{2}\right]$ in Figure $8 B$ that corresponded to the fractional GFP-PLC $\delta$-PH translocation derived from the fluorescence signals in Fig. 3, we calculated the relationship between membrane $\left[\mathrm{PIP}_{2}\right]$ and $\mathrm{M}$ channel availability using the experimental data of Zhang et al. (2003) for the activation of KCNQ2/3 channels by $\mathrm{DiC}_{8}-\mathrm{PIP}_{2}$, with an $\mathrm{EC}_{50}$ value of $87 \mu \mathrm{M}$ and Hill slope of 1.35 . This gives a maximum channel availability of $81 \%$ at $\left[\mathrm{PIP}_{2}\right]$ of $261 \mu \mathrm{M}$. Starting here, we calculated the reduction in M-channel availability (and hence percentage inhibition of $\mathrm{M}$ current) with increasing concentrations of oxotremorine-M as predicted from the observed fluorescence increase. As shown in Fig. 9A, this provided a reasonable fit to the experimentally observed concentration-inhibition data. The maximum observed fluorescence signal corresponds to an $83 \%$ decrease in calculated [ $\left.\mathrm{PIP}_{2}\right]$, in broad agreement with that (75\%) reported by Willars et al. (1998) after strong carbachol stimulation in neuroblastoma cells.

\section{Effect of PI5-K on M-current inhibition}

We also tested how far the fluorescence measurements predicted the changes in $\mathrm{M}$-current inhibition by oxotremorine-M after overexpression of PI5-K (compare Figs. $9 B$ and $4 B, C$ ). In these experiments, oxotremorine- $\mathrm{M}$ increased cytosolic fluorescence $\left(\Delta F / F_{0}\right)$ under control conditions by a mean of $+72 \%$ (Fig. $4 C$ ). With conversion to fractional translocation and taking $\left[\mathrm{PIP}_{2}\right]_{\text {Rest }}$ of $261 \mu \mathrm{M}$, this equates (from Fig. $8 B$ ) to a 93\% decrease in [PIP ${ }_{2}$ ] and thence (from Zhang et al., 2003) to $86 \%$ inhibition of available $\mathrm{M}$ current (Fig. 9B, filled bars). PI5-K expression increased apparent $\left[\mathrm{PIP}_{2}\right]_{\text {Rest }}$ to a mean value of $693 \mu \mathrm{M}$ (Fig. 7, Table 1) but reduced $\Delta F / F_{\mathrm{o}}$ to $+9 \%$. This predicts a much smaller decrease in $\left[\mathrm{PIP}_{2}\right]$ of $21.8 \%$ and consequently a much-reduced $(2.3 \%)$ inhibition of M current (Fig. 9B, filled bars, +PI5-K). Thus, although the values for $\mathrm{M}$-current inhibition calculated from the fluorescence signals are slightly greater in controls and slightly less in PI5-K overexpressing neurons than those observed experimentally (Fig. 9B, open bars and filled bars, respectively), the reduction in M-current inhibition calculated from the change in fluorescence signals matches the observed reduction reasonably well. Interestingly, the fluorescence data also suggests that the con-

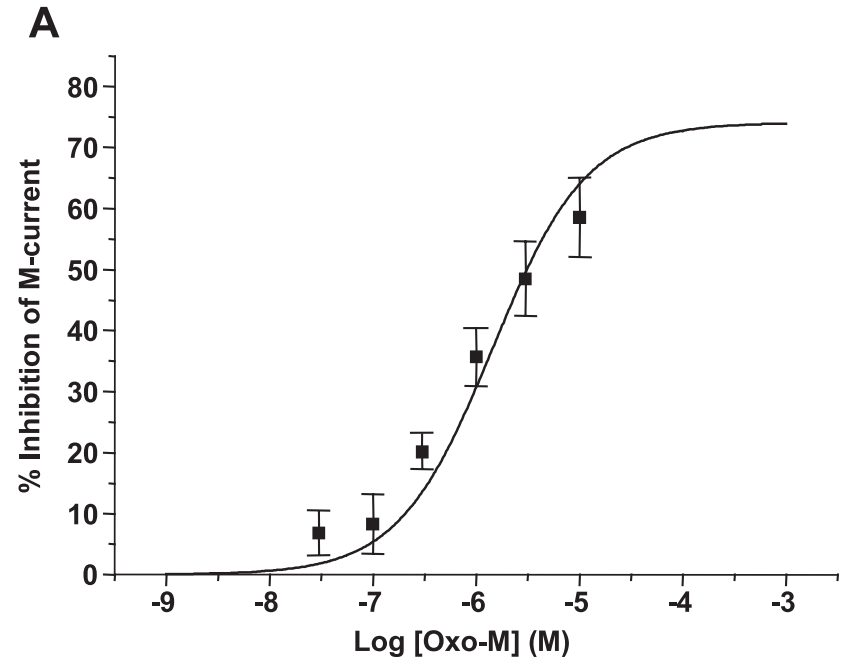

B

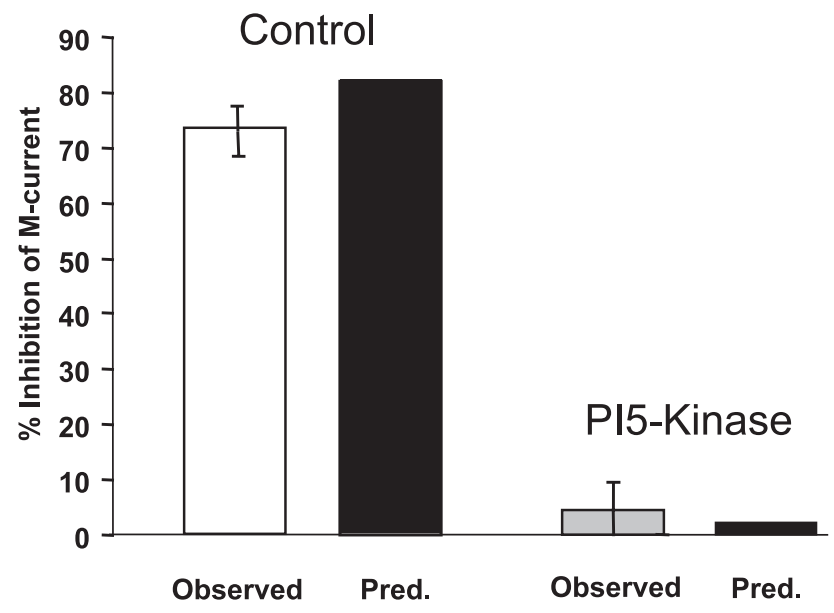

Figure 9. M-current inhibition calculated from the fluorescence measurements. Concentrations of $\mathrm{PIP}_{2}$ before and during application of oxotremorine-M were calculated from observed $\Delta F / F_{0}$ using the numerical data in Figure $8 B$ and converted to fractional $M$-channel availability (and thence percentage inhibition) from the KCNQ2/3 channel gating data of Zhang et al. (2003) (see Results). Numerical values used for the calculations are listed in Table 1. $\boldsymbol{A}$, $M$-current inhibition calculated from the fluorescence data in Figure 3 (smooth curve) superimposed on the mean data points for the observed inhibition in Figure 3. The equation for the curve is $y=y_{\max } \cdot x^{\mathrm{nH}} /\left(x^{\mathrm{nH}}+K^{\mathrm{nH}}\right)$, where $x=\log [0 \times 0-M](M), K=-5.8 \pm 0.1$ (SEM; mean 1.6 $\mu \mathrm{M}[0 \mathrm{x} 0-\mathrm{M}]), y_{\max }=74.0 \pm 6.1 \%$ inhibition, and $n_{\mathrm{H}}=0.96 \pm 0.13 . B$, Solid bars, Predicted (Pred.) M-current inhibition produced by $10 \mu \mathrm{m}$ oxotremorine-M in control and PI5-K overexpressing neurons calculated from the fluorescence data in Figure 4C. Open and shaded bars are the observed percentage inhibition in the experiments shown in Figure 4D. Error bars indicate SEMs of observed data ( $n$ values are as in Figs. 3 and 4).

centration of intracellular $\mathrm{IP}_{3}$ attained after application of oxotremorine-M was, if anything, reduced (from 5.8 to $3.6 \mu \mathrm{M}$ ). Although this may seem surprising, it would accord with the absence of any clear increase in the bradykinin-induced $\mathrm{Ca}^{2+}$ signal after PI5-K overexpression, perhaps implying that PLCactivated PIP ${ }_{2}$ hydrolysis induced by high-agonist concentrations is saturated at resting $\left[\mathrm{PIP}_{2}\right]$. Finally, the apparent increase in resting $\left[\mathrm{PIP}_{2}\right]$ would be expected to increase M-channel availability from 81 to $94 \%$. This would have been undetectable as an increase in resting current in our experiments, because it lies within the scatter of our measurements. Thus, whereas the mean current was $\sim 10 \%$ greater in PI5-K overexpressing neurons, the difference was not significant. 


\section{Discussion}

In the present experiments, we were able to record both $\mathrm{M}$-current inhibition and $\mathrm{PIP}_{2}$ hydrolysis (by fluorescence monitoring of GFP-PLC $\delta$-PH translocation) simultaneously in single sympathetic neurons after stimulation of endogenous $G_{q / 11^{-}}$ coupled receptors. As a result, we clearly demonstrated that M-current inhibition in these neurons is accompanied by $\mathrm{PIP}_{2}$ hydrolysis and that (for cholinergic inhibition at least) there is a close correlation between the two events with respect to both time course and concentration dependence. In addition, procedures that modified the extent of $\mathrm{PIP}_{2}$ hydrolysis, such as inhibition of PLC or overexpression of PI5-K, produced parallel changes in both readouts of receptor activation. This provides strong evidence that M-current inhibition in sympathetic neurons does indeed result from $\mathrm{PIP}_{2}$ hydrolysis, as previously inferred from other work (see the Introduction).

The following question then arises: does channel closure result directly from the hydrolysis of $\mathrm{PIP}_{2}$ and hence reduction of $\mathrm{PIP}_{2} \mathrm{M}$-channel gating or from an effect of a downstream product such as $\mathrm{Ca}^{2+}$ or DAG?

\section{Cholinergic inhibition}

The present data point strongly toward the upstream " $\mathrm{PIP}_{2^{-}}$ depletion" hypothesis as the primary mechanism for M-current inhibition by oxotremorine-M for two main reasons. First, overexpression of PI5-K increased apparent resting membrane $\mathrm{PIP}_{2}$ levels but strongly reduced $\mathrm{M}$-current inhibition. Hence, it is unlikely that inhibition results from the action of a product of $\mathrm{PIP}_{2}$ hydrolysis. Second, oxotremorine-M produced a quantitatively comparable inhibition of GIRK currents, which are also known to be regulated by $\mathrm{PIP}_{2}$ (see the Introduction), and this inhibition was equally reduced by PI5-K overexpression.

We used the fluorescence data to calculate the levels of $\mathrm{PIP}_{2}$ available to the GFP-PLC $\delta$-PH probe and changes therein after oxotremorine- $\mathrm{M}$ application and thence, using the experimental data of Zhang et al. (2003) for $\mathrm{DiC}_{8}-\mathrm{PIP}_{2}$ activation of KCNQ2/3 channels to assess how far our experimental observations accord with the $\mathrm{PIP}_{2}$-gating hypothesis. Although there are a number of uncertainties and limitations to this approach (most of which are considered above), the results are internally consistent (at least, for steady-state conditions) and fairly accurately predict the observed concentration-dependence of oxotremorine-induced M-current inhibition (Fig. 9A). They also predict reasonably well the observed reduction of M-current inhibition on overexpressing PI5-K (Fig. 9B). In the latter case, this appears to result from the fact that the increased PIP $_{2}$ levels are not matched by an increased rate of agonist-induced $\mathrm{PIP}_{2}$ hydrolysis, as determined by the calculated cytosolic $\mathrm{IP}_{3}$ levels.

We emphasize that these calculations were made solely to determine how far our fluorescence data could be extrapolated to interpret our M-current data. Suh et al. (2004) used a more comprehensive and dynamic "model cell" approach, incorporating $\mathrm{PIP}_{2}$ channel gating, to analyze the kinetics of mAChR-Gqmediated inhibition of expressed KCNQ2/3 channels. Apart from the inclusion by Suh et al. (2004) of the various kinetic parameters necessary for time course simulation, one difference is that their model starts from a higher basal density of membrane $\mathrm{PIP}_{2}$ molecules $\left[5000 / \mu \mathrm{m}^{2}\right.$; closer to that deduced by Xu et al. (2003) from biochemical data]. For $\mathrm{PIP}_{2}$ gating of $\mathrm{M}$ channels, they then assumed a power function of 1.8 with $76 \%$ channel availability at resting $\left[\mathrm{PIP}_{2}\right]$. This provided an excellent fit to their experimental data but implies a much higher apparent dissociation equilibrium constant $\left(\sim 1 \mathrm{mM}\right.$ intramembrane $\left.\left[\mathrm{PIP}_{2}\right]\right)$ than that observed experimentally for activation of KCNQ2/3 channels by exogenous $\mathrm{DiC}_{8}-\mathrm{PIP}_{2}\left(K_{\mathrm{M}}, 87 \mu \mathrm{M} ; n_{\mathrm{H}}, 1.35\right)$ (Zhang et al., 2003). Our (lower) estimates of membrane $\left[\mathrm{PIP}_{2}\right]$ are more compatible with these experimental data. From this, we reason that the apparent concentration (and density) of $\mathrm{PIP}_{2}$ as seen by the GFP-PLC $\delta$-PH peptide (and displaceable by intracellular $\mathrm{IP}_{3}$ ), although lower than those deduced from biochemical data, might plausibly reflect the effective concentration as seen by the membrane-subjacent $\mathrm{PIP}_{2}$-binding domain of the $\mathrm{M}$ channels. Nevertheless, we recognize that the values for $\left[\mathrm{PIP}_{2}\right]$ derived from the $\mathrm{IP}_{3}$ displacement tests are subject to errors in, for example, assumptions of GFP-PLC $\delta$-PH-binding constants or estimates of CMVR. Thus, if the ratio of binding constants was 10:1 $\left(\mathrm{PIP}_{2}: \mathrm{IP}_{3}\right)$ rather than $20: 1$, this would double the calculated $\left[\mathrm{PIP}_{2}\right]$, although this would be offset if we underestimated CMVR by the same factor. Clearly, it would be interesting to assess the $\mathrm{IP}_{3}$-displacement method that we used to estimate $\left[\mathrm{PIP}_{2}\right]$ in other cells for which more biochemical data are available, such as the neuroblastoma cells used by Willars et al. (1998) and Xu et al. (2003).

Another difference from the model used by Suh et al. (2004) is that we allowed PIP to fall in parallel with $\mathrm{PIP}_{2}$ during $\mathrm{PIP}_{2}$ hydrolysis, similar to the experimental observations of Willars et al. (1998), whereas a much smaller decline of PIP was predicted in the Suh et al. (2004) model. Relaxing this constraint would not have a major effect on our calculations of M-current inhibition, because the amount of GFP-PLC $\delta$-PH bound by PIP is much less than that bound by $\mathrm{PIP}_{2}$ [and even smaller taking the estimates of relative PIP and $\mathrm{PIP}_{2}$ concentrations used by Suh et al. (2004)], but it would reduce our estimates of $\mathrm{IP}_{3}$ production.

\section{The action of bradykinin}

We have less quantitative information regarding the effect of bradykinin, mostly because desensitization limits the scope of experiments. Qualitatively, however, the effects of bradykinin on $\mathrm{M}$ currents and on GFP-PLC $\delta$-PH translocation and the changes therein on PI5-K overexpression were similar to those of oxotremorine-M, implying that the primary events were the same. Nevertheless, there were two notable differences between the effects of these two agonists: NCS-1 expression selectively reduced the effects of bradykinin but not those of oxotremorine-M, and bradykinin did not affect GIRK currents.

Both differences might be explained if the release of intracellular $\mathrm{Ca}^{2+}$ played a key role in the effect of bradykinin (Cruzblanca et al., 1998; Delmas et al., 2002; Gamper and Shapiro, 2003). Thus, NCS- 1 is a $\mathrm{Ca}^{2+}$-binding protein, and its upregulation of PI4-K activity is enhanced by $\mathrm{Ca}^{2+}$ (Zhao et al., 2001). Hence, the release of $\mathrm{Ca}^{2+}$ by bradykinin might accelerate PIP (and subsequently $\mathrm{PIP}_{2}$ ) synthesis in the presence of excess NCS-1 and thereby reduce the depletion of membrane $\mathrm{PIP}_{2}$ required for effective M-current inhibition (Winks and Marsh, 2003). Although we could not obtain evidence for any substantial changes in $\left[\mathrm{PIP}_{2}\right]$ in NCS-1 overexpressing neurons in the presence of $200 \mathrm{~nm}$ intracellular [ $\mathrm{Ca}^{2+}$ ], micromolar concentrations are required to enhance PI4-kinase activation (Zhao et al., 2001); such concentrations might well be attained in bradykininreceptor submembrane "microdomains" (Delmas et al., 2002) after application of bradykinin. An initial increase in $\mathrm{PIP}_{2}$ synthesis by bradykinin has been noted in neuroblastoma cells (Xu et al., 2003). The concomitant reduction in the fluorescence signal may then be attributed to increased competition with $\mathrm{IP}_{3}$ for the fluorescent probe by the higher maintained levels of PIP 2 . A similar effect mediated by $\mathrm{Ca}^{2+}$-dependent activation of PI4-K by 
endogenous NCS-1 may also explain why bradykinin was unable to inhibit the GIRK channels, because (unlike M channels) these are relatively insensitive to intracellular $\mathrm{Ca}^{2+}$ but bind $\mathrm{PIP}_{2}$ with a higher apparent affinity than KCNQ channels $\left(\mathrm{EC}_{50}\right.$ value for $\mathrm{diC}_{8}-\mathrm{PIP}_{2}, 17.7 \mu \mathrm{M}$ ) (Rohacs et al., 2003). Gamper et al. (2004) have advanced a similar hypothesis to explain the resistance of $\mathrm{PIP}_{2}$-gated $\mathrm{Ca}^{2+}$ channels to bradykinin and showed that $\mathrm{Ca}^{2+}$ channels become inhibited by bradykinin when $\mathrm{PIP}_{2}$ synthesis is reduced by wortmannin or on overexpressing a dominantnegative NCS- 1 construct.

How does one explain the reduction in M-current inhibition by bradykinin in PI5-K overexpressing cells on the $\mathrm{Ca}^{2+}$ hypothesis? A key factor here is that $\mathrm{Ca}^{2+}$ closes $\mathrm{M}$ channels through the intermediation of calmodulin (Gamper and Shapiro, 2003). Because one of the binding sites for calmodulin on the KCNQ2 channel overlaps the putative binding site for $\mathrm{PIP}_{2}$ [Delmas et al. (2004), their Fig. 4], $\mathrm{Ca}^{2+}$ might close $\mathrm{M}$ channels by reducing their affinity for $\mathrm{PIP}_{2}$. For example, an approximately fourfold increase in the dissociation constant (from 87 to $360 \mu \mathrm{M}$ ) without change in $\left[\mathrm{PIP}_{2}\right]_{\text {Rest }}$ would suffice to produce the $\sim 52 \%$ inhibition in Fig. $4 B$. Because there is no increase (and possibly a decrease) in the $\mathrm{Ca}^{2+}$ signal in PI5-K overexpressing cells (see Results), at the higher resting $\mathrm{PIP}_{2}$ concentration, a comparable affinity shift would produce a smaller $(\sim 25 \%)$ inhibition of $M$ current.

An additional degree of complexity is added by the observation that $\mathrm{mAChR}$-induced activation of protein kinase $\mathrm{C}$ enhances the sensitivity of $\mathrm{M}$ channels to $\mathrm{mAChR}$-induced inhibition, through phosphorylation of the constituent KCNQ channels by channel-bound A-kinase anchoring proteinattached protein kinase C (Hoshi et al., 2003). This enhancement (amounting to a threefold shift of the concentration-response curve) might also reflect a change in the affinity of $\mathrm{PIP}_{2}$ for the $\mathrm{M}$ channels, perhaps by modifying the binding of calmodulin (which is already partly activated at resting intracellular $\left[\mathrm{Ca}^{2+}\right]$ ) (Gamper and Shapiro, 2003), because the phosphorylation sites overlap the second calmodulin binding site (Delmas et al., 2004). If so, modification of $\mathrm{PIP}_{2}$ binding might provide the unifying common path for the multifarious regulators of $\mathrm{M}$-channel activity. Additional information regarding the nature of the $\mathrm{PIP}_{2}$ binding site on $\mathrm{M} / \mathrm{KCNQ}$ channels and the factors that affect this binding would clearly be helpful.

\section{References}

Agard DA, Hiraoka Y, Shaw P, Sedat JW (1989) Fluorescence microscopy in three dimensions. Methods Cell Biol 30:353-377.

Bender K, Wellner-Kienitz M-C, Pott L (2002) Transfection of a phosphatidyl-4-phosphate 5-kinase gene into rat atrial myocytes removes inhibition of GIRK current by endothelin and $\alpha$-adrenergic agonists. FEBS Lett 529:356-360.

Bernheim L, Mathie A, Hille B (1992) Characterization of muscarinic receptor subtypes inhibiting $\mathrm{Ca}^{2+}$ current and $\mathrm{M}$ current in rat sympathetic neurons. Proc Natl Acad Sci USA 89:9544-9548.

Bofill-Cardona E, Vartian N, Nanoff C, Freissmuth M, Boehm S (2000) Two different signaling mechanisms involved in the excitation of rat sympathetic neurons by uridine nucleotides. Mol Pharmacol 57:1165-1172.

Brown DA (1988) M-currents. In: Ion channels, Vol 1 (Narahashi T, ed), pp 55-99. New York: Plenum.

Brown DA, Adams PR (1980) Muscarinic suppression of a novel voltagesensitive K current in a vertebrate neurone. Nature 283:673-676.

Burgoyne RD, O'Callaghan DW, Hasdemir B, Haynes LP, Tepikin AV (2004) Neuronal $\mathrm{Ca}^{2+}$-sensor proteins: multitalented regulators of neuronal function. Trends Neurosci 27:203-209.

Canepari M, Nelson L, Papgeorgiou G, Corrie JE, Ogden D (2001) Photochemical and pharmacological evaluation of 7-nitroindolyl and 4-methoxy-7-nitroindolyl amino acids as novel, fast caged neurotransmitters. J Neurosci Methods 112:29-42.

Castleman KR (1996) Digital image processing. Saddle River, NJ: Prentice-Hall.

Cruzblanca H, Koh DS, Hille B (1998) Bradykinin inhibits M current via phospholipase $\mathrm{C}$ and $\mathrm{Ca}^{2+}$ release from $\mathrm{IP}_{3}$-sensitive $\mathrm{Ca}^{2+}$ stores in rat sympathetic neurons. Proc Natl Acad Sci USA 95:7151-7156.

Davis JN, Rock CO, Cheng M, Watson JB, Ashmun RA, Kirk H, Kay RJ, Rooiusel MF (1997) Complementation of growth factor-dependent mitogenic signaling by a truncated type I phosphatidylinositol 4-phosphate 5-kinase. Mol Cell Biol 17:7398-7406.

Delmas P, Wanaverbecq N, Abogadie FC, Mistry M, Brown DA (2002) Signalling microdomains define the specificity of receptor-mediated $\mathrm{Ins}_{3}$ pathways in neurons. Neuron 34:209-220.

Delmas P, Crest M, Brown DA (2004) The functional organization of phospholipase-C signaling microdomains in neurons. Trends Neurosci 27:41-47.

Del Rio E, Bevilacqua JA, Marsh SJ, Halley P, Caulfield MP (1999) Muscarinic $\mathrm{M}_{1}$ receptors activate phosphoinositide turnover and $\mathrm{Ca}^{2+}$ mobilization in rat sympathetic neurones, but this signalling pathway does not mediate M-current inhibition. J Physiol (Lond) 520:101-111.

Fernandez-Fernandez JM, Wanaverbecq N, Halley P, Caulfield MP, Brown DA (1999) A role for $M_{2}$ receptors in the muscarinic activation of $G$ protein-gated $\mathrm{K}^{+}$(GIRK) channels expressed in isolated rat sympathetic neurones. J Physiol (Lond) 515:631-637.

Ferrell JE, Huestes WH (1984) Phosphoinositide metabolism and the morphology of human erythrocytes. J Cell Biol 98:1992-1998.

Filippov AK, Fernandez-Fernadez JM, Marsh SJ, Simon J, Barnard EA, Brown DA (2004) Activation and inhibition of neuronal G proteingated inwardly-rectifying $\mathrm{K}^{+}$channels by $\mathrm{P} 2 \mathrm{Y}$ nucleotide receptors. Mol Pharmacol 66:468-477.

Fink CC, Slepchenko B, Moraru II, Schaff J, Watras J, Loew L (1999) Morphological control of inositol-1,4,5-trisphosphate-dependent signals. J Cell Biol 147:929-935.

Ford CP, Stemkowski PL, Light PE, Smith PA (2003) Experiments to test the role of phosphatidyl 4,5-bisphosphate in neurotransmitter-induced M-channel closure in bullfrog sympathetic neurons. J Neurosci 23:4931-4941.

Gamper N, Shapiro MS (2003) Calmodulin mediates $\mathrm{Ca}^{2+}$-dependent modulation of M-type $\mathrm{K}^{+}$channels. J Gen Physiol 122:17-31.

Gamper N, Reznikov V, Yamada Y, Yang J, Shapiro MS (2004) Phosphatidyl 4,5-bisphosphate signals underlie receptor-specific $\mathrm{G}_{\mathrm{q} / 11}$-mediated modulation of N-type $\mathrm{Ca}^{2+}$ channels. J Neurosci 24:10980-10992.

Garcia P, Gupta R, Shah S, Morris AJ, Rudge SA, Scarlata S, Petrova V, McLaughlin S, Rebecchi MJ (1995) The pleckstrin homology domain of phospholipase C- $\delta_{1}$ binds with high affinity to phosphatidylinositol 4,5bisphosphate in bilayer membranes. Biochemistry 34:16228-16234.

Haley JE, Abogadie FC, Delmas P, Dayrell M, Vallis Y, Milligan G, Caulfield MP, Brown DA, Buckley NJ (1998) The $\alpha$ subunit of $\mathrm{G}_{\mathrm{q}}$ contributes to muscarinic inhibition of the M-type potassium current in sympathetic neurons. J Neurosci 18:4521-4531.

Hilgemann DW, Feng S, Nasuhoglu C (2001) The complex and intriguing lives of PIP $_{2}$ with ion channels and transporters. Sci STKE RE19.

Hill JJ, Peralta EG (2001) Inhibition of a $\mathrm{G}_{\mathrm{i}}$-activated potassium channel (GIRK1/4) by the $\mathrm{G}_{\mathrm{q}}$-coupled M1 muscarinic acetylcholine receptor. J Biol Chem 276:5505-5510.

Hirose K, Kadowaki S, Tanabe M, Takeshima H, Iino M (1999) Spatiotemporal dynamics of inositol 1,4,5-trisphosphate that underlies complex $\mathrm{Ca}^{2+}$ mobilization patterns. Science 284:1527-1530.

Hoshi N, Zhang JS, Omaki M, Takeuchi T, Yokoyama S, Wanaverbecq N, Langeberg LK, Yoneda Y, Scott JD, Brown DA, Higashida H (2003) AKAP150 signaling promotes suppression of the M-current by muscarinic agonists. Nat Neurosci 6:564-571.

Ishihara H, Shibasaki Y, Kizuki N, Katagiri H, Yazaki Y, Asanao T, Oka Y (1996) Cloning of cDNAs encoding two isoforms of $68-\mathrm{kDa}$ type I phosphatidylinositol-4-phosphate-5-kinase. J Biol Chem 271:23611-23614.

Jentsch TJ (2000) Neural KCNQ potassium channels: physiology and role in disease. Nat Rev Neurosci 1:21-30.

Jones S, Brown DA, Milligan G, Willer E, Buckley NJ, Caulfield MP (1995) Bradykinin excites rat sympathetic neurons by inhibition of $\mathrm{M}$ current through a mechanism involving $\mathrm{B}_{2}$ receptors and $\mathrm{G} \alpha_{\mathrm{q} / 11}$. Neuron 14:399-405. 
Kobrinsky E, Mirshahi T, Zhang H, Jin T, Logothetis D (2000) Receptormediated hydrolysis of plasma membrane messenger $\mathrm{PIP}_{2}$ leads to $\mathrm{K}^{+}$ current desensitization. Nat Cell Biol 2:507-514.

Koizumi S, Ross P, Wilars GB, Challis JA, Taverna E, Francolini M, Bootman MD, Lipp P, Inoue K, Roder J, Jeromin A (2002) Mechanism underlying the neuronal calcium sensor-1-evoked enhancement of exocytosis in PC12 cells. J Biol Chem 277:30315-30324.

Lei Q, Talley EM, Bayliss DA (2001) Receptor-mediated inhibition of G protein-coupled inwardly rectifying potassium channels involves $\mathrm{G} \alpha_{\mathrm{q}}$ family subunits, phospholipase $\mathrm{C}$, and a readily diffusible second messenger. J Biol Chem 276:16720-16730.

Lemmon MA, Ferguson K, O’Brien R, Sigler PB, Schlessinger J (1995) Specific and high-affinity binding of inositol phosphates to an isolated pleckstrin homology domain. Proc Natl Acad Sci USA 92:10472-10476.

Loussouarn G, Park K-H, Bellocq C, Baro I, Charpentier F, Escande D (2003) Phosphatidylinositol-4,5-bisphosphate, $\mathrm{PIP}_{2}$, controls KCNQ1/KCNE1 voltage-gated potassium channels: a functional homology between voltage-gated and inward rectifier $\mathrm{K}^{+}$channels. EMBO J 22:5412-5421.

Marrion NV (1993) Selective reduction of one mode of M-channel gating by muscarine in sympathetic neurons. Neuron 11:77-84.

Marrion NV (1997) Control of M-current. Annu Rev Physiol 59:483-504.

Marrion NV, Smart TG, Marsh SJ, Brown DA (1989) Muscarinic suppression of the M-current in the rat sympathetic ganglion is mediated by receptors of the M1-subtype. Br J Pharmacol 98:557-573.

Meyer T, Wellner-Kienitz MC, Biewald A, Bender K, Eickel A, Pott L (2001) Depletion of phosphatidylinositol-4,5-bispophate by activation of phospholipase C-coupled receptors causes slow inhibition but not desensitization of $\mathrm{G}$ protein-gated inward rectifier $\mathrm{K}^{+}$current in atrial myocytes. J Biol Chem 276:5650-5658.

Nahorski SR, Young KW, Challis RJ, Nash MS (2003) Visualizing phosphoinositide signaling in single neurons gets a green light. Trends Neurosci 26:444-452.

Nakanishi S, Catt KJ, Balla T (1995) A wortmannin-sensitive phosphatidylinositol 4-kinase that regulates hormone-sensitive pools of inositolphospholipids. Proc Natl Acad Sci USA 92:5317-5321.

Rae J, Cooper K, Gates P, Watsky M (1991) Low access resistance perforated patch recordings using amphotericin B. J Neurosci Methods 37:15-26.

Rajebhosale M, Greenwood S, Vidugiriene J, Jeromin A, Hilfiker S (2003) Phosphatidylinositol 4-OH kinase is a downstream target of neuronal calcium sensor-1 in enhancing exocytosis in neuroendocrine cells. J Biol Chem 278:6075-6084.

Rhee SG (2001) Regulation of phosphoinositide-specific phospholipase C. Annu Rev Biochem 70:281-312.

Rohacs T, Lopes CM, Jin T, Ramdya PP, Molnar Z, Logothetis DE (2003) Specificity of activation by phosphoinositides determines lipid regulation of Kir channels. Proc Natl Acad Sci USA 100:745-750.

Ruiz-Velasco V, Ikeda SR (1998) Heterologous expression and coupling of $\mathrm{G}$ protein-gated inwardly-rectifying $\mathrm{K}^{+}$channels in adult rat sympathetic neurons. J Physiol (Lond) 513:761-773.

Runnels LW, Yue L, Clapham DE (2002) The TRPM7 channel is inactivated by $\mathrm{PIP}_{2}$ hydrolysis. Nat Cell Biol 4:329-336.

Schaad NC, DeCastro E, Nef S, Hegi S, Hinrichsen R, Martone ME, Ellisma MH, Sikkink R, Sygush J, NefP (1996) Direct modulation of calmodulin targets by the neuronal calcium sensor NCS-1. Proc Natl Acad Sci USA 93:9253-9258.

Selyanko AA, Brown DA (1996) Intracellular calcium directly inhibits potassium M-channels in excised membrane patches from rat sympathetic neurons. Neuron 16:151-162.

Selyanko AA, Stansfeld CE, Brown DA (1992) Closure of potassium M-channels by muscarinic acetylcholine-receptor stimulants requires a diffusible messenger. Proc R Soc Lond B Biol Sci 250:119-125.

Stauffer TP, Ahn S, Meyer T (1998) Receptor-induced transient reduction in plasma membrane $\operatorname{PtdIns}(4,5) \mathrm{P}_{2}$ concentration monitored in living cells. Curr Biol 8:343-346.

Suh B-C, Hille B (2002) Recovery from muscarinic modulation of M-current channels requires phosphatidylinositol 4,5-bisphosphate synthesis. Neuron 35:507-520.

Suh B-C, Horowitz L, Hirdes W, Mackie K, Hille B (2004) Regulation of KCNQ2/KCNQ3 current by G protein cycling: the kinetics of receptormediated signaling by $\mathrm{G}_{\mathrm{q}}$. J Gen Physiol 123:1-22.

Van der Wal J, Habets R, Varnai P, Balla T, Jalink K (2001) Monitoring agonist-induced phospholipase $\mathrm{C}$ activation in live cells by fluorescence resonance energy transfer. J Biol Chem 276:15337-15344.

Vanhaesebroeck B, Leevers SJ, Ahmadi K, Timms J, Katso R, Driscoll PC, Woscolsk R, Parker PJ, Waterfield MD (2001) Synthesis and function of 3-phosphorylated inositol lipids. Annu Rev Biochem 70:535-602.

Varnai P, Balla T (1998) Visualization of phosphoinositides that bind peckstrin homology domains: calcium and agonist-induced dynamic changes and relationship to myo- $\left[{ }^{3} \mathrm{H}\right]$ inositol-labelled phosphoinositide pools. J Cell Biol 143:501-510.

Wanaverbecq N, Marsh SJ, Al-Qatari M, Brown DA (2003) The plasma membrane calcium ATPase as a major mechanism for intracellular calcium regulation in neurons from the rat superior cervical ganglion. J Physiol (Lond) 550:83-101.

Wang H-S, Pan Z, Shi WM, Brown BS, Wymore RS, Cohen IS, Dixon JE, McKinnon D (1998) KCNQ2 and KCNQ3 potassium channel subunits: molecular correlates of the M-channel. Science 282:1890-1893.

Willars GB, Nahorski SR, Challis RAJ (1998) Differential regulation of muscarinic acetylcholine receptor-sensitive polyphosphoinositide pools and consequences for signaling in human neuroblastoma cells. J Biol Chem 273:5037-5046.

Winks JS, Marsh SJ (2003) Agonist-induced phosphatidyl-4,5-bisphosphate $\left(\mathrm{PIP}_{2}\right)$ hydrolysis and $\mathrm{M}$-current inhibition in sympathetic neurons: effects of the neuronal calcium-sensor protein NCS-1. J Physiol (Lond) 547P:C75.

Winks JS, Tatulian L, Filippov AK, Abogadie FC, Marsh SJ, Brown DA (2003) Effect of PI(4)P-5 kinase over-expression on transmitter-induced inhibition of M- and GIRK-currents. Soc Neurosci Abstr 29:368.18.

$\mathrm{Xu}$ C, Watras J, Loew LM (2003) Kinetic analysis of receptor-activated phosphoinositide turnover. J Cell Biol 161:779-791.

Zhang H, Craciun LC, Mirshahi T, Rohacs T, Lopes CMB, Jin T, Logothetis D (2003) PIP $_{2}$ activates KCNQ channels, and its hydrolysis underlies receptor-mediated inhibition of M currents. Neuron 37:963-975.

Zhao X, Varnai P, Tuymetova G, Balla A, Toth ZE, Oker-Blom C, Roder J, Jeromin A, Balla T (2001) Interaction of neuronal calcium sensor-1 (NCS-1) with phosphatidylinositol 4-kinase $\beta$ stimulates lipid kinase activity and affects membrane trafficking in COS-7 cells. J Biol Chem 278: 40183-40189. 